\title{
High-throughput Screening of Vanadium (IV) Oxide via Continuous Hydrothermal Flow Synthesis Reactor
}

\author{
Mai K. Tran ${ }^{a, b, \dagger}$, Elizabeth G. Rasmussen ${ }^{a, c, \dagger}$, Elena Shevchenko ${ }^{d}$, Jie Li ${ }^{a *}$
}

a. Applied Materials Division, Argonne National Laboratory, 9700 South Cass Avenue, Lemont, Illinois 60439, United States

b. Department of Materials Science and NanoEngineering, Rice University, 6100 Main Street, Houston, Texas 77005, United States

c. Department of Mechanical Engineering, University of Washington, Box 352600, Seattle, Washington 98195-0001, United States

d. Center of Nanoscale Materials, Argonne National Laboratory, 9700 South Cass Avenue, Lemont, Illinois 60439, United States

$\dagger$ These authors contributed equally.

* Corresponding author: jieli@anl.gov

KEYWORDS: Vanadium dioxide, scalable synthesis, nanoparticle synthesis, continuous flow, hydrothermal, supercritical fluid 


\begin{abstract}
The synthesis of inorganic nanoparticles using continuous hydrothermal flow synthesis (CHFS) reactor systems is an up-and-coming process to manufacture high quality nanomaterials with singular control of the experimental parameters on the scale of seconds opposed to hours. VO2based systems manufactured using an autoclave reactor lack scalability, and current commercial products feature particle sizes too large for feasible application. In this paper, detailed implementation of a CHFS system that can operate at and above supercritical water conditions (22.06 $\mathrm{MPa}$ at $374^{\circ} \mathrm{C}$ ) is described. Control over the CHFS system's temperature, flow rate, and precursor concentration parameters allowed the tunability of size, crystallinity, and shape of VO2 nanoparticles to be investigated across seven studies. The resulting VO2 nanoparticles were characterized for size, shape, morphology, and crystallinity using dynamic light scattering (DLS), scanning electron microscopy (SEM), and x-ray diffraction (XRD). This investigation resulted in new operating procedures that enable the synthesis of high-quality, uniform, spherical, and pure M-phase VO2 nanoparticles under $50 \mathrm{~nm}$ in diameter in the residence time of a few seconds. Additionally, the procedure described in this paper is performed in a single step, thus eliminating the tedious post-annealing process.
\end{abstract}




\section{INTRODUCTION}

Vanadium (IV) oxide $\left(\mathrm{VO}_{2}\right)$ has garnered attention for its use in energy-efficient thermochromic smart window films and building materials. ${ }^{1,2} \mathrm{VO}_{2}$ 's reversible transformation from an insulating monoclinic phase (M-phase) to a metallic rutile phase (R-phase) above a critical transition temperature of $68^{\circ} \mathrm{C}$ makes it an ideal window film material that can passively allow in or reflect certain wavelengths of light. ${ }^{3}$ Previous studies have shown that this structural reversibility can be used to let in near-infrared (NIR) wavelengths felt as heat during cold, winter months (as $\mathrm{VO}_{2}$ in M-phase is present), and block this NIR heat during hot, summer months (as $\mathrm{VO}_{2}$ in R-phase is present). ${ }^{4}$ However, despite the extensive historical work done on the material, few affordable commercialized products for $\mathrm{VO}_{2}$ exist on the market today. It is thought that due to the challenge of working with multivalent vanadium which exhibits various stable oxidation states $\left(\mathrm{V}^{2+}, \mathrm{V}^{3+}, \mathrm{V}^{4+}, \mathrm{V}^{5+}\right)$ in addition to its many polymorphs phases (B-, A-, M-, D-, and P-phase), the processing techniques are too complicated, requiring multiple steps that consume both time and energy. ${ }^{5-8}$

Traditionally, synthesis of M-phase $\mathrm{VO}_{2}$ nanoparticles is achieved via a batch-method using an autoclave. The batch-method synthesis of the reactants and additives takes extended periods of time, from 12-48 hours, and yields nanoparticles in various sizes and shapes from rods, nanowires, and nano-belts, to snowflakes and spheres, all requiring an additional annealing step to convert the material fully from B-phase to A-phase, and then finally M-phase. ${ }^{5,6,9}$ In comparison, continuous flow reactors can be a technology disruptor in the inorganic nanoparticle synthesis industry. While the idea of high-pressure, high-heat initially does not sound energy-efficient or environmentally-friendly, when looking at the continuous manufacturing of an entire product in an industrial setting, continuous flow reactors as compared to batch methods actually reduce the 
overall energy consumption of a plant by allowing mass-production of high yields in less time and proper design and reuse of heat energy, ultimately saving money in materials, manufacturing, and energy costs ${ }^{10}$. Nanoparticle synthesis using continuous flow hydrothermal (CFHT) systems has long been explored for various application ranging from catalysis, optics, and electronics, to energy storage and healthcare. ${ }^{11,12}$ As compared to those processes that make use of organic solvents, using water as the solvent enables a more green, economic, and environmentally-friendly process technology. ${ }^{13}$ Beyond being a scalable synthesis method, continuous flow reactors also provide precise control over operating conditions like flow rate, temperature, and pressuretunable parameters that can precisely lead to the emergence of certain features of the material, like size and shape. ${ }^{14,15}$

In addition to a continuous flow method, raising water above the critical temperature of $373^{\circ} \mathrm{C}^{16}$ and critical pressure of $22.06 \mathrm{MPa}^{17}$ (i.e. to operate in the supercritical phase), allows for the scalability of $\mathrm{M}$-phase $\mathrm{VO}_{2}$ nanoparticles. Supercritical phase water has the distinct properties of allowing optimum supersaturation to occur, maximizing nucleation rates by more than $10^{3} .^{18}$ Additionally, supercritical phase fluids have much lower viscosity, density, and dielectric constants allowing formerly soluble polar inorganic salts to become insoluble due to the highly hydrolyzing environment; this allows precipitation at much higher rates than in otherwise ambient conditions. ${ }^{19-21}$ Furthermore, using water as a solvent can lead to economic savings and is also a much safer material to work, as opposed to highly acidic or highly alkaline media used in many batch syntheses. ${ }^{13}$

In the case of $\mathrm{VO}_{2}$ nanoparticles for smart window applications, it is desirable to manufacture large quantities of homogeneous $\mathrm{M}$-phase $\mathrm{VO}_{2}$ nanoparticles under 50 to minimize the light scattering reduction. ${ }^{1,22}$ This work demonstrates that continuous flow reactor with 
supercritical water can be used to manufacture scalable amounts of ultra-small, uniform M-phase $\mathrm{VO}_{2}$ nanoparticles that are of a high interest for smart window films' applications.

\section{MATERIALS AND METHODS}

All chemicals used in the experiments were purchased from Sigma-Aldrich and used as received without further purification, unless otherwise stated.

\section{Precursor Preparation}

Following precursor preparation procedures described in literature, the starting reagent for the experiments was a $0.0356 \mathrm{M}\left[\mathrm{V}^{4+}\right]$ precursor solution made using 1 mol vanadium pentoxide $\left(\mathrm{V}_{2} \mathrm{O}_{5}, 1.29 \mathrm{~g}\right)$ to $3 \mathrm{~mol}$ oxalic acid dihydrate $\left(\mathrm{C}_{2} \mathrm{H}_{2} \mathrm{O}_{4} \cdot 2 \mathrm{H}_{2} \mathrm{O}, 2.69 \mathrm{~g}\right)$, measured using an analytical balance (Mettler Toledo, ME54TE) ${ }^{23}$ The solid powders were mixed with $400 \mathrm{~mL}$ of deionized water (DI). The resulting opaque, brown solution was then placed in an ultrasonication bath (Branson, 8510) at $60^{\circ} \mathrm{C}$ for 3 hours or until the mixture turned a clear, aqua blue. For the final optimized experiments, a precursor solution of $1 \mathrm{~mol} \mathrm{~V}_{2} \mathrm{O}_{5}(1.29 \mathrm{~g})$ to $4 \mathrm{~mol} \mathrm{C}_{2} \mathrm{H}_{2} \mathrm{O}_{4} \cdot 2 \mathrm{H}_{2} \mathrm{O}(3.59$ g), was used. This mixture formed a clear, but deeper blue color following an ultrasonication bath at $60^{\circ} \mathrm{C}$ for 3 hours. The hydrolysis and dehydration pathway for this reaction is shown in Equation $1-3$.

$$
\begin{gathered}
\left.\mathrm{V}_{2} \mathrm{O}_{5}+4\left(\mathrm{C}_{2} \mathrm{H}_{2} \mathrm{O}_{4} \cdot 2 \mathrm{H}_{2} \mathrm{O}\right) \rightarrow\left[(\mathrm{VO})_{2}\left(\mathrm{C}_{2} \mathrm{O}_{4}\right)_{3}\right)\right]^{2-}+2 \mathrm{H}_{3} \mathrm{O}^{+}+2 \mathrm{CO}_{2}+9 \mathrm{H}_{2} \mathrm{O} \\
\left.\left[(\mathrm{VO})_{2}\left(\mathrm{C}_{2} \mathrm{O}_{4}\right)_{3}\right)\right]^{2-}+2 \mathrm{H}_{3} \mathrm{O}^{+} \rightarrow 2 \mathrm{VOC}_{2} \mathrm{O}_{4}+\mathrm{CO}+\mathrm{CO}_{2}+3 \mathrm{H}_{2} \mathrm{O} \\
2 \mathrm{VOC}_{2} \mathrm{O}_{4} \rightarrow 2 \mathrm{VO}_{2}+2 \mathrm{CO}+2 \mathrm{CO}_{2}
\end{gathered}
$$

Photographs of the precursor preparation are available in the Supporting Information, Figure S1 and Figure S2. 


\section{Reactor Configuration and Operation}

A continuous flow hydrothermal (CFHT) reactor was custom-built within a walk-in chemical fume hood, as shown in Figure 1. The rector includes 1) precursor and deionized (DI) water high pressure pumps (Teledyne SSI HF300, Pulsafeeder HL 55) to deliver precursor mixture and heating water; 2) a cast-in brown water heater (Tempco, Model CHX-20138,6 kW@ $208 \mathrm{VAC}$ ) to heat the water to the temperature exceeding supercritical point of $374^{\circ} \mathrm{C}$; 3) 0.5 inch outer diameter (OD) counter-flow tubing reactor with wall thickness of 0.083 inch where cold precursor and hot water mix and reaction occurs; and 4) a coil heat exchanger (Sentry Inc., Model\#: TSR4225) to cool the colloidal effluent down. The system pressure is controlled by using two TESCOM back pressure regulators (Model\#: BPR 26-1763-24-688) in series to elongate the lifetime. The temperature, pressure, and flow rate can be tuned independently. The system also featured several safety measures including 1) check valves to prevent back-flow; 2) seven thermocouples connected to a data acquisition system for real-time temperature control and monitoring back-pressure regulators, 3) proportional pressure relief valves to discharge if overpressurized; and 4) an American Society of Mechanical Engineers (ASME)-stamped and certified rupture disc that would immediately burst in an overpressure situation, ${ }^{24}$ All pipes were constructed of either 0.5 inch OD (0.083 in wall thickness) high pressure 316 stainless steel material or 0.25 inch OD (0.049 wall thickness). Before any experiments were conducted, the reactor was pressure tested with deionized water (DI) water for any leaks to ensure safe operation. After experiments, the reactor was flushed with DI water for 30 minutes and finally a valve was opened after the heat exchanger that allowed a vacuum pump to clean any residual products from within the reactor. These residual products were collected in a backflush collection beaker. A 
photograph of the reactor with key components identified is included in the Supporting Information, Figure S3.

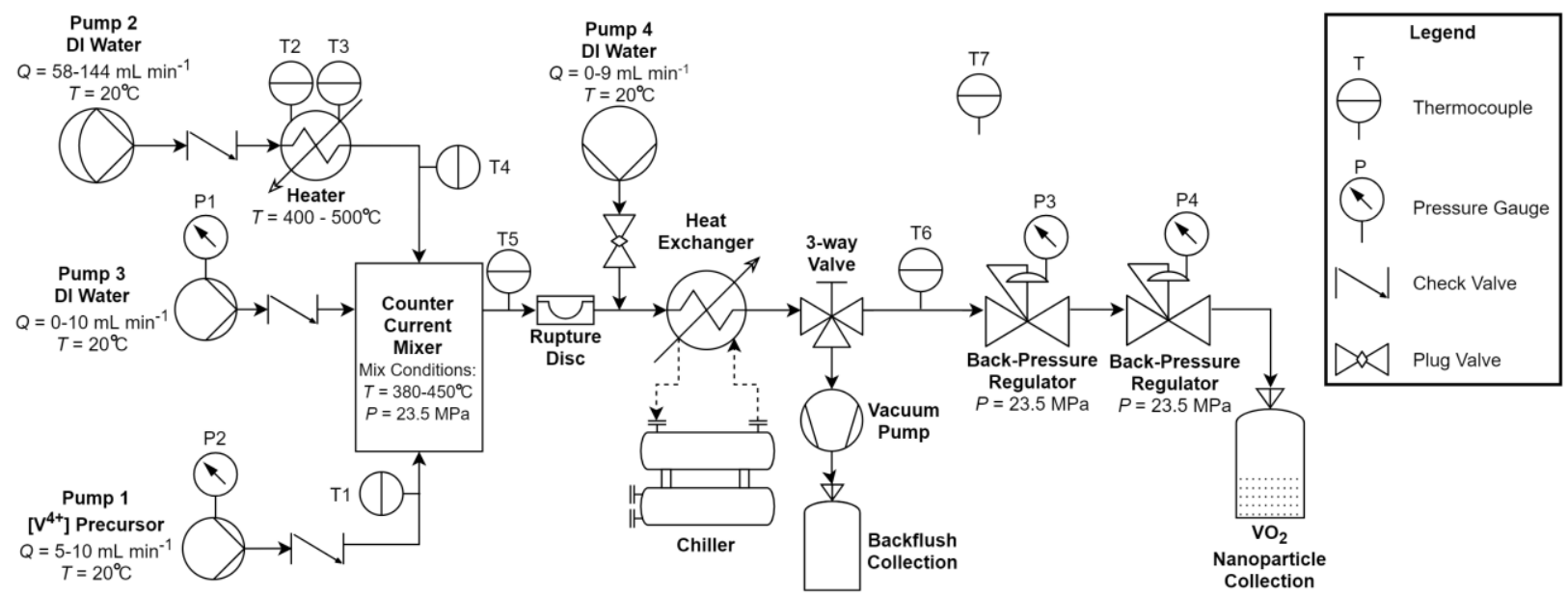

Figure 1. A schematic of the continuous flow hydrothermal (CFHT) synthesis reactor. The experiments begin at Pump 1 and Pump 2, which respectively flow vanadium precursors and DI water heated above the critical temperature (at supercritical phase) into the mixing section. The nanoparticles form in the mixing section before going through a heat exchanger, connected to the chiller. The cooled colloidal solution then passes through a pair of back-pressure regulators and is collected as the final nanoparticle product. Pump 3 and Pump 4 add fluid and additionally cool the exiting fluid. A backflush valve, vacuum pump, and collection container were also built into the reactor for cleaning between experiments. Six thermocouples monitor the temperature throughout the reactor in real-time, and a seventh thermocouple measures the ambient atmospheric conditions.

In a typical experiment, a recirculation chiller (MTI Corporation, KJ6200) was the first to be initiated. The chiller is connected to a circulation heat exchanger (Sentry, DTC-SSA/CUA-41-1) to lower the temperature of hot fluid effluent that passes right after the reaction zone. Next, Pump 1 (Teledyne SSI, HF-300), Pump 2 (Pulsafeeder, 55HL), Pump 3 (Knauer, LS40P), and Pump 4 (Teledyne SSI, Accuflow Series 3), all were initially connected to DI water, set to the desired flow rate, and turned on. The reactor pressure was gradually increased above the critical pressure of water $(22.06 \mathrm{MPa})$ and stabilized to $23.5 \pm 0.5 \mathrm{MPa}$ using two back pressure regulators 
in series (Tescom, 26-1700). Internal pressure was monitored using vibration and corrosion resistant pressure gauges (McMaster-Carr). After reaching a stable operating pressure, a cast-in circulation heater (Tempco, CHX20138) was then turned on to raise the DI water temperature from Pump 2 above water's critical temperature of $374^{\circ} \mathrm{C}$. To prevent heat loss from the system to the surroundings, an insulation blanket (Tempco) surrounded the cast-in heater. A modified flow reactor (ThalesNano, Phoenix) with built in two-stage heaters and insulation was used to maintain a constant temperature throughout the mixing section of the reactor. Details on the operation of this two-stage heater are included in the Supporting Information. High-heat ceramic insulation (Owens Corning) was wrapped around all pipes and fittings. Once the temperature within the reactor reached steady state, the vanadium precursor solution was connected to Pump 1 to officially start nanoparticle synthesis. The precursor solution from Pump 1 entered the mixing section and mixed with the heated supercritical phase water from Pump 2 in a counter-current geometry, and the $\mathrm{VO}_{2}$ nanoparticle product is formed. At the end of the inner inlet tube where the supercritical phase water exited, a 316 stainless steel filter with $20 \mu \mathrm{m}$ averaged pore size (Mott Corporation) was attached to aid in uniform dispersion of the supercritical water into the precursor liquid. The hot solution then exited the mixing section of the reactor. At the exit of mixing section Pump 3 and Pump 4 allowed for an option to add either an organic capping agent or room temperature DI water to the colloidal solution. The option of an organic capping agent could serve the purpose to make core-shell particles, the option of DI water could serve to increase mixing and decrease the temperature of the colloidal solution. In this paper only DI water was used. Thus, following the mixing section, the colloidal solution was immediately quenched with a stream of room temperature DI water from Pump 3 and Pump 4 and then passed through the heat exchanger and back-pressure regulators. When Pump 3 or Pump 4 were not used for an experiment, possible back 
flow or dead zones were eliminated by using a valve in the case of Pump 3, and a cap in the case of Pump 4 at the connection locations. A schematic of the counter-current mixing section and reactor section, including the inlet locations for Pump 3 and Pump 4, is shown in Figure 2 and detailed measurements are shown in Supporting Information, Figure S4. Finally, the end product of $\mathrm{VO}_{2}$ nanoparticles dispersed in water, hereby known as the resulting colloidal solution, was collected at the end of the system.

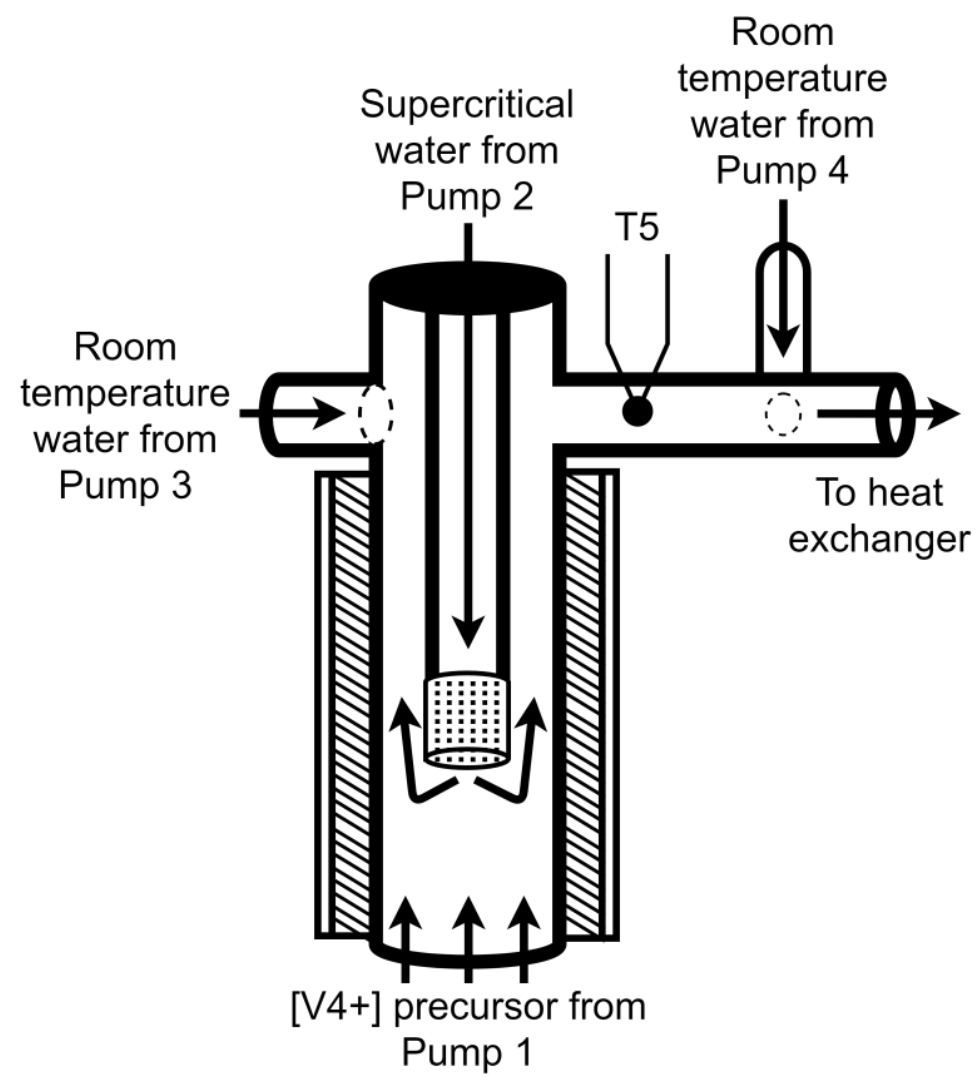

Figure 2. A schematic of the CFHT reactor's mixing section. Precursor solution from Pump 1 enters the mixing section from the bottom. Supercritical phase water from Pump 2 enters the mixing section from the top and flows through an inner inlet pipe to exit through a $20 \mu \mathrm{m} 316$ stainless steel filter. The colloidal fluid then exits the mixing section where a thermocouple (T5) records the reaction temperature. Then the colloidal solution flows through the heat exchanger. Dotted circles indicate the inlet locations of room temperature DI water from Pump 3 and Pump 4. The hash markings on the outside of the outer tube represent the heaters and insulation (ThalesNano, Pheonix) that serve to maintain a constant mixing section temperature. 
During a typical experiment, the fluid temperature at different points of the reactor was measured using six high temperature Inconel type K thermocouples (Omega, TJ36) with accuracy of $\pm 2.2^{\circ} \mathrm{C}$. The first thermocouple (T1) was placed in the fluid line after Pump 1, which was expected to maintain room temperature conditions. Two more thermocouples were placed within and just outside the circulation heater as a control (T2) and limit measurement (T3) as a safety measure. The fourth thermocouple (T4) was placed in the fluid line right before the mixing section to measure the supercritical phase water temperature upon entering the mixing section. The fifth thermocouple was placed in the fluid line right after the mixing section (T5) to measure the reaction temperature at which the nanoparticles formed. The sixth thermocouple (T6) was placed in the fluid line after the heat exchanger to ensure the colloidal solution had cooled sufficiently before running through the back-pressure regulator. A seventh type K thermocouple (T7) with a probe for air (McMaster-Carr) was placed inside the fume hood above the reactor system to monitor the ambient air temperature.

\section{Experimental Outline}

Throughout this paper, the seven studies explored the effect of: Study 1) supercritical phase water $\left(\mathrm{scH}_{2} \mathrm{O}\right)$ flow rate from Pump 2, experiments labeled "A"; Study 2) precursor concentration, experiments labeled "B"; Study 3) varying $\mathrm{scH}_{2} \mathrm{O}$ flow rate at elevated temperatures using diluted precursor defined in study 2, experiments labeled "C" and "D"; Study 4) changing the $\mathrm{V}_{2} \mathrm{O}_{5}$ to $\mathrm{C}_{2} \mathrm{H}_{2} \mathrm{O}_{4} \cdot 2 \mathrm{H}_{2} \mathrm{O}$ precursor molar ratio from 1:3 to 1:4, experiments labeled "E"; Study 5) additional reactor section flow rate from Pump 4, experiments labeled "F"; Study 6) precursor flow rate from Pump 1, experiments labeled "G”; and Study 7) additional mixing section flow rate from Pump 3, which refer to the experiments labeled "H". Table 1 outlines the experimental conditions studied in this paper across the seven studies. 
Table 1. Experiential Conditions Employed for Seven Parametric Studies Synthesizing $\mathrm{VO}_{2}$ Nanoparticles in a Continuous Flow Hydrothermal (CFHT) Reactor with $\mathrm{scH}_{2} \mathrm{O}$.

\begin{tabular}{|c|c|c|c|c|c|}
\hline \multirow{2}{*}{ Experiment } & \multirow{2}{*}[\mathrm{V}^{4+}]{$(\mathrm{M})$} & \multicolumn{4}{|c|}{ Volumetric Flow Rate $\left(\mathrm{mL} \cdot \mathrm{min}^{-1}\right)$} \\
\hline & & Pump 1 & Pump 2 & Pump 3 & Pump 4 \\
\hline \multicolumn{6}{|c|}{ Study 1: $\mathrm{scH}_{2} \mathrm{O}_{\text {Flow Rate (Pump 2) }}$} \\
\hline A1 & 0.0356 & 10 & 58 & 10 & 9 \\
\hline A2 & 0.0356 & 10 & 86 & 10 & 9 \\
\hline A3 & 0.0356 & 10 & 115 & 10 & 9 \\
\hline A4 & 0.0356 & 10 & 144 & 10 & 9 \\
\hline A5 & 0.0356 & 10 & 172 & 10 & 9 \\
\hline \multicolumn{6}{|c|}{ Study 2: Precursor Concentration } \\
\hline B1 & 0.0356 & 10 & 144 & 10 & 9 \\
\hline B2 & 0.0178 & 10 & 144 & 10 & 9 \\
\hline B3 & 0.01187 & 10 & 144 & 10 & 9 \\
\hline B4 & 0.00712 & 10 & 144 & 10 & 9 \\
\hline B5 & 0.00356 & 10 & 144 & 10 & 9 \\
\hline \multicolumn{6}{|c|}{ Study 3: $\mathrm{scH}_{2} \mathrm{O}$ Flow Rate (Pump 2) at Elevated Temperature } \\
\hline $\mathrm{C} 1$ & 0.01187 & 10 & 58 & 10 & 9 \\
\hline $\mathrm{C} 2$ & 0.01187 & 10 & 86 & 10 & 9 \\
\hline $\mathrm{C} 3$ & 0.01187 & 10 & 115 & 10 & 9 \\
\hline $\mathrm{C} 4$ & 0.01187 & 10 & 172 & 10 & 9 \\
\hline D1 & 0.01187 & 10 & 58 & 10 & 9 \\
\hline D2 & 0.01187 & 10 & 86 & 10 & 9 \\
\hline D3 & 0.01187 & 10 & 115 & 10 & 9 \\
\hline D4 & 0.01187 & 10 & 144 & 10 & 9 \\
\hline D5 & 0.01187 & 10 & 172 & 10 & 9 \\
\hline \multicolumn{6}{|c|}{ Study 4: Molar Ratio-Precursor changed from 1:3 to a 1:4 ratio of $\mathrm{V}_{2} \mathrm{O}_{5}$ to $\mathrm{C}_{2} \mathrm{H}_{2} \mathrm{O}_{4} \cdot 2 \mathrm{H}_{2} \mathrm{O}$} \\
\hline E1 & 0.01187 & 10 & 144 & 10 & 9 \\
\hline E2 & 0.01187 & 10 & 115 & 10 & 9 \\
\hline \multicolumn{6}{|c|}{ Study 5: Additional Reactor Section Flow Rate (Pump 4) } \\
\hline F1 & 0.01187 & 10 & 115 & 10 & 9 \\
\hline F2 & 0.01187 & 10 & 115 & 10 & 0 \\
\hline F3 & 0.01187 & 10 & 115 & 10 & 0 \\
\hline F4 & 0.01187 & 10 & 115 & 10 & 0 \\
\hline \multicolumn{6}{|c|}{ Study 6: Precursor Flow Rate (Pump 1) } \\
\hline G1 & 0.01187 & 5 & 115 & 10 & 0 \\
\hline G2 & 0.01187 & 5 & 115 & 10 & 0 \\
\hline G3 & 0.01187 & 10 & 115 & 10 & 0 \\
\hline G4 & 0.01187 & 15 & 115 & 10 & 0 \\
\hline \multicolumn{6}{|c|}{ Study 7: Additional Mixing Section Flow Rate (Pump 3) } \\
\hline $\mathrm{H} 1$ & 0.01187 & 10 & 115 & 10 & 9 \\
\hline $\mathrm{H} 2$ & 0.01187 & 10 & 115 & 10 & 0 \\
\hline H3 & 0.01187 & 10 & 115 & 0 & 0 \\
\hline $\mathrm{H} 4$ & 0.01187 & 10 & 115 & 0 & 0 \\
\hline
\end{tabular}




\section{Material Characterization}

Immediately following an experiment, a $15 \mathrm{~mL}$ sample was extracted from the experiment's colloidal solution, allowed to cool to room temperature, and probed by a Dynamic Light Scattering (DLS) particle analyzer (MicroTrac, NanoTrack Flex). Using an intensity distribution calculated over three runs with a run time of $60 \mathrm{~s}$ each and assuming spherically shaped particles, the intensity average and number average particle sizes were recorded. The intensity average $\left(\mathrm{M}_{\mathrm{I}}\right)$, also known as the Z-average or the intensity based harmonic mean, gives an indication of a particle distribution weighted by the scattered intensity from the particle, so the presence of larger particles will cause this average to also be large. The number average $\left(\mathrm{M}_{\mathrm{N}}\right)$ on the other hand, can give a better indication of the average based on the sizes from a total quantity of particles, i.e. larger particles' higher scattering intensity will not overshadow the measurement of the smaller particles. ${ }^{25}$ Both methods were used to gain insight into the $\mathrm{VO}_{2}$ particle distribution of the experiments.

The remaining colloidal solution from an experiment was then centrifuged (Beckman Coulter, Optima L-100 XP) three times at 40,000 relative centrifugal force (rcf) for 10 min each. After pouring the supernatant off the first run, the second and third repetitions of centrifugation were rinsed with DI water and ethanol, respectively. The nanoparticles were left to dry overnight at room temperature and atmospheric pressure. X-ray diffraction (XRD) analysis was used to determine the phase composition of the resulting nanoparticles. XRD samples were prepared by dispersing $10 \mathrm{mg}$ of nanoparticles onto a silicon wafer, then analysis was performed (Bruker, AXS D8 Advance) with $\mathrm{CuK} \alpha(\lambda=1.5418 \AA)$ radiation at room temperature over the angular range from $10^{\circ}$ to $80^{\circ} 2 \theta$ at a scanning rate of $0.5 \mathrm{deg} \cdot \mathrm{min}^{-1}$. Scanning electron microscopy (SEM) was used to reveal particle morphology and confirm nanoparticle size from DLS characterization. For SEM 
characterization, about $10 \mathrm{mg}$ of nanoparticles were adhered to carbon tape attached to a silicon wafer, then analysis (Jeol, JSM-7500F) was conducted using a $20 \mathrm{keV}$ electron beam.

\section{Flow Characterization}

Flow characteristics in the CFHT reactor system are performed by calculation of the Reynolds number (Re), which characterizes the degree of mixing and residence time; parameters that can thus describe how heat is distributed among nanoparticles and allow conversion to Mphase for each experiment. The temperature is defined at the location where the colloidal solution exits the mixing section, T5 (Figure 2). The internal pressure of the CFHT system is defined at P3, being 23.5 MPa. The equation for the Reynolds Number $(R e)$ was calculated using the equation:

$$
R e=\frac{\rho u D}{\mu}
$$

where $\rho$ is the density of the fluid in $\mathrm{kg} \cdot \mathrm{m}^{-3}, u$ is the flow rate in $\mathrm{m} \cdot \mathrm{s}^{-1}, D$ is the diameter of the reactor section tube in $\mathrm{m}$, and $\mu$ is the dynamic viscosity of the fluid measured in $\mathrm{Pa} \cdot \mathrm{s} .{ }^{26}$ The values of flow rate and diameter were physical dimensions obtained from the experimental setup in the reaction zone of the reactor, while the density and viscosity values were obtained from the National Institute of Standards and Technology (NIST) RefProp. ${ }^{27}$ A Re value greater than 4000 indicates turbulent flow, while a Re value less than 2100 is classified as laminar flow, and any flow falling in between $2100-4000$ is considered transitional. ${ }^{28}$

Residence time in the mixing section and the reactor section of the CFHT system was calculated for each experiment. Calculations were completed by first converting volumetric flow rate, $Q$, to mass flow rate, $\dot{m}$, for each of the four pumps, given the density from of liquid's temperature and pressure being pumped $\left(20^{\circ} \mathrm{C}, 23.5 \mathrm{MPa}\right)$. Then the $\dot{m}$ for the mixing and reactor section were defined. The $\dot{m}$ for the mixing section was then defined as the sum of $\dot{m}$ for Pump 1 
and Pump 2 whereas the $\dot{m}$ for the reactor section was defined as the sum of the $\dot{m}$ for all the pumps, Pump 1-4. The volume in the mixing section was defined as the area of the inner inlet pipe minus the area of the outer pipe multiplied by the length of the mixing section. Here, the mixing section length is defined as the distance from the end of the inner inlet pipe to the reactor section pipe's centerline as commonly done in counter current mixing sections. ${ }^{29}$ The volume for the flow in the reactor section was defined by the inner diameter of the reactor section pipe and the length of the reactor section. The density of the fluid in the mixing and reactor sections was defined from NIST RefProp at the isobaric pressure of $23.5 \mathrm{MPa}$ and using the thermocouple data, T5, for the temperature of the colloidal solution exiting the mixing section. From the density and $\dot{m}$, the velocity and consequently residence time of the colloidal solution was derived. A figure with dimensions and a step-by-step calculation for residence time is included in the Supporting Information, Figure S3.

\section{RESULTS AND DISCUSSION}

$\mathrm{VO}_{2}$ nanoparticles were synthesized in a continuous flow (CFHT) reactor using supercritical water $\left(\mathrm{scH}_{2} \mathrm{O}\right)$ as the solvent. Over the course of seven studies different effects on the $\mathrm{VO}_{2}$ nanoparticle size, morphology, and phase were observed. An example overview of the system temperatures during operation, including start-up and cool-down phases, is in Figure S5, and thermocouple data for all experiments is included in the Supporting Information. The Phoenix twostage heater surrounding the mixing section ensured that the nanoparticles on the wall are also evenly heated during the mixing. The upper-stage heater is maintained at $330^{\circ} \mathrm{C}$ and the lowerstage heater is maintained at $270^{\circ} \mathrm{C}$ for Study 1, 2, and 3-C. For Study 3-D, the upper and lower heaters are maintained at $450^{\circ} \mathrm{C}$ and $360^{\circ} \mathrm{C}$ respectively. Study 4 had upper and lower heater temperatures of $450^{\circ} \mathrm{C}$ and $400^{\circ} \mathrm{C}$ respectively. The differences in the Phoenix heating 
temperatures were adjusted to ensure that the temperature of the colloidal solution exiting the mixing section (T5) was maintained above the critical temperature of water $\left(374^{\circ} \mathrm{C}\right)$ and to ensure particles are able to achieve full M-phase conversion.

The synthesis of $\mathrm{VO}_{2}$ nanoparticles is based on the reaction between vanadium pentoxide and oxalic acid dihydrate $\left(\mathrm{C}_{2} \mathrm{H}_{2} \mathrm{O}_{4} \cdot 2 \mathrm{H}_{2} \mathrm{O}\right)$ that results in the formation of $\mathrm{VOC}_{2} \mathrm{O}_{4}$ that later decomposes. Decomposition of $\mathrm{VOC}_{2} \mathrm{O}_{4}$ is accompanied by release of gases such as $\mathrm{CO}$ and $\mathrm{CO}_{2}$ (Eq. 3) than was directly observed in collection beaker. Depending on the experimental conditions the color of the resulting colloidal solution varied from black-gray to blue-gray in color. The turbidity of the solution depended on the given experiment's flow rate and precursor concentrations. Upon centrifugation, the colloidal solutions yielded yellow-tinted supernatants when a 1:3 ratio of vanadium pentoxide to oxalic acid is used. However, when the ratio is changed to $1: 4$, the supernatant solution is clear indicating the complete conversion of the vanadium precursor.

Different flow rates for synthesis were explored and it was found that $\mathrm{scH}_{2} \mathrm{O}$ flow rates between $60 \mathrm{~mL} \cdot \mathrm{min}^{-1}$ and $150 \mathrm{~mL} \cdot \mathrm{min}^{-1}$ allowed the most consistence in maintaining constant temperatures for experiments. As the non-linear heat transfer effects near the critical point have been presented near the critical point in previous work, the flow rate below $60 \mathrm{~mL} \cdot \mathrm{min}^{-1}$ and above $150 \mathrm{~mL} \cdot \mathrm{min}^{-1}$ are to be avoided in future work. ${ }^{30}$ The size of synthesized nanoparticles was routinely analyzed using a DLS particle analyzer. In turn, morphology and crystallinity are studied by SEM imaging and XRD. The role of thermodynamics in the system was also studied by analysis of residence time calculated from the temperature of the $\mathrm{scH}_{2} \mathrm{O}$ (T4) and colloidal solution (T5). Seven parametric studies explore the parametric space available in CFHT reactor systems. The 
following section presents the results and discussions for the seven different studies. Each study was based on the optimization of the parameters in the previous set of the experiments.

\section{Effect of Supercritical Water $\left(\mathrm{scH}_{2} \mathrm{O}\right)$ Flow Rate}

In this set of experiments, called "Study 1" in Table 1, the $\mathrm{scH}_{2} \mathrm{O}$ volumetric flow rate, Pump 2, for was varied between $58 \mathrm{~mL} \cdot \mathrm{min}^{-1}$ and $172 \mathrm{~mL} \cdot \mathrm{min}^{-1}$, leading to a total system flow rate between $87 \mathrm{~mL} \cdot \mathrm{min}^{-1}$ and $201 \mathrm{~mL} \cdot \mathrm{min}^{-1}$. Table 2 presents the flow rate, key temperatures $\mathrm{T} 4$ ( $\mathrm{scH}_{2} \mathrm{O}$ entering the mixing section) and $\mathrm{T} 5$ (colloidal solution exiting the mixing section), residence times, DLS, XRD, and SEM material characterization results for experiments A1-A5.

Table 2. Experiments in Study 1: $\mathrm{scH}_{2} \mathrm{O}$ Flow Rate ( Pump 2) Effect on $\mathrm{VO}_{2}$ nanoparticles synthesized in a CFHT reactor- Experimental Parameters, Residence Time, Re, and DLS, XRD, SEM Material Characterization

\begin{tabular}{|c|c|c|c|c|c|c|c|c|c|c|c|}
\hline \multirow[b]{2}{*}{ Exp. } & \multirow{2}{*}{$\begin{array}{c}\text { Total/ } \\
\text { Pump } 2 \\
\text { Flow Rate } \\
\left(\mathrm{mL} \cdot \mathrm{min}^{-1}\right)\end{array}$} & \multicolumn{2}{|c|}{$\begin{array}{c}\text { Average } \\
\text { Temperature }\left({ }^{\circ} \mathrm{C}\right) \\
\end{array}$} & \multicolumn{3}{|c|}{ Residence Time (s) } & \multirow[b]{2}{*}{$\operatorname{Re}$} & \multicolumn{2}{|c|}{ DLS } & \multirow[b]{2}{*}{$\begin{array}{l}\text { XRD } \\
\text { Phase }\end{array}$} & \multirow[b]{2}{*}{ SEM $^{\dagger}$} \\
\hline & & $\mathrm{T} 4$ & T5 & $\begin{array}{l}\text { Mixing } \\
\text { Section }\end{array}$ & $\begin{array}{l}\text { Reactor } \\
\text { Section }\end{array}$ & Total & & $\mathrm{M}_{\mathrm{I}}$ & $\mathrm{M}_{\mathrm{N}}$ & & \\
\hline A1 & $87 / 58$ & 520.8 & 383.5 & 0.51 & 2.01 & 2.51 & 7,177 & 370.0 & 145.1 & $\mathrm{~A}, \mathrm{M}$ & FP, $\mathrm{S}$ \\
\hline A2 & $115 / 86$ & 394.8 & 380.6 & 0.48 & 2.04 & 2.52 & 8,146 & 383.0 & 108.9 & $\mathrm{~A}, \mathrm{M}$ & FP, R, S \\
\hline A3 & $144 / 115$ & 391.1 & 382.2 & 0.30 & 1.34 & 1.64 & 11,367 & 276.7 & 101.5 & A & $F P, R, S$ \\
\hline A4 & $173 / 144$ & 387.9 & 381.3 & 0.27 & 1.20 & 1.47 & 13,143 & 162.5 & 88.5 & $\mathrm{~A}, \mathrm{M}$ & - \\
\hline A5 & $201 / 172$ & 387.5 & 379.0 & 0.37 & 1.67 & 2.04 & 10,934 & 136.5 & 70.7 & $\mathrm{~A}, \mathrm{M}$ & $\mathrm{R}, \mathrm{S}$ \\
\hline
\end{tabular}

$\uparrow$ Abbreviations used for SEM morphology: FP for Flaky Plates, R for Rods, and S for Spheres

The DLS particle analyzer showed the intensity average particle size decreased from 370.0

$\mathrm{nm}$ to $136.5 \mathrm{~nm}$, and the number average decreased from $145 \mathrm{~nm}$ to $70.7 \mathrm{~nm}$, at increasing flow rates (Figure 3a). At higher flow rates, the reaction mixture spends less time in the hot reaction zone. As a result, shorter reaction time leads to smaller nanoparticles. Additionally, it is observed that more turbulent mixing conditions, as indicated by the Re number, generally led to smaller particle sizes. Experiment A5 did not follow these observed trends, which could be due to temperature fluctuations occurring in the cast heater and in turn the $\mathrm{scH}_{2} \mathrm{O}$ entering the mixing section during the experiment as the flow rate for $\mathrm{scH}_{2} \mathrm{O}$ was $172 \mathrm{ml} / \mathrm{min}$, above the mentioned $160 \mathrm{ml} / \mathrm{min}$, see Figure S10. The corresponding SEM images, revealed the structures with 
elongated (Figure 3b, c) and rounded (Figure 3d) particle morphology. The formation of elongated structures is previously explained as a result of the shear forces from the mixing of the precursor and supercritical water in the reaction zone that affects the growth kinetics. ${ }^{10}$ Almost all experimental conditioned tested in this set of experiments resulted in the formation of $\mathrm{VO}_{2}$ nanoparticles with A-phase peaks (Figure 3e). $\mathrm{VO}_{2}$ (A), as referenced by JCPDS card No. 420876 have peaks corresponding to X-ray diffraction at (110), (102), (220), and (330) planes. ${ }^{31,}$ ${ }^{32}$ However, in contrast to other studies which often exhibit B-phase when using additive-free techniques, this CFHT system has shown the co-existence of A- and M-phase $\mathrm{VO}_{2}$. Moreover, the samples synthesized at the highest flow rate had only M-phase. The $\mathrm{VO}_{2}$ (M-phase) peaks observed for the samples synthesized under the lowest flow rate likely had more chance to undergo a phase transition as a result of a longer residence time since the nanoparticles are in the reaction zone longer. It is thought also that the Phoenix two-stage heater set at $330^{\circ} \mathrm{C}$ and $270^{\circ} \mathrm{C}$ are not sufficiently high enough to convert the nanoparticles at the wall of the reactor during the mixing. The appearance of M-phase as evidenced by the (011) peak at $2 \theta=29.0^{\circ}$ under the highest flow rate $\left(201 \mathrm{~mL} \cdot \mathrm{min}^{-1}\right.$, experiment A5 in Table 2$)$, is hypothesized to be directly connected with the increase of the residence time in the reactor section by $38 \%$ as compared to experiment $\mathrm{A} 4$. The increase in residence time was due to a temperature (T5) decrease by $2^{\circ} \mathrm{C}$ for experiment A5. Such a small decrease in temperature is usually not impactful, but as experiments were conducted near the critical point $\left(373^{\circ} \mathrm{C}\right.$ for water) and specifically near the pseudo-critical point $\left(379^{\circ} \mathrm{C}\right.$ at 23.5 $\mathrm{MPa}$ ), large changes in the thermophysical properties of $\mathrm{scH}_{2} \mathrm{O}$ occur. Thus, the $2^{\circ} \mathrm{C}$ temperature decrease resulted in a $48.5 \%$ increase in density, from $235 \mathrm{~kg} \cdot \mathrm{m}^{-3}$ to $349 \mathrm{~kg} \cdot \mathrm{m}^{-3}$. 


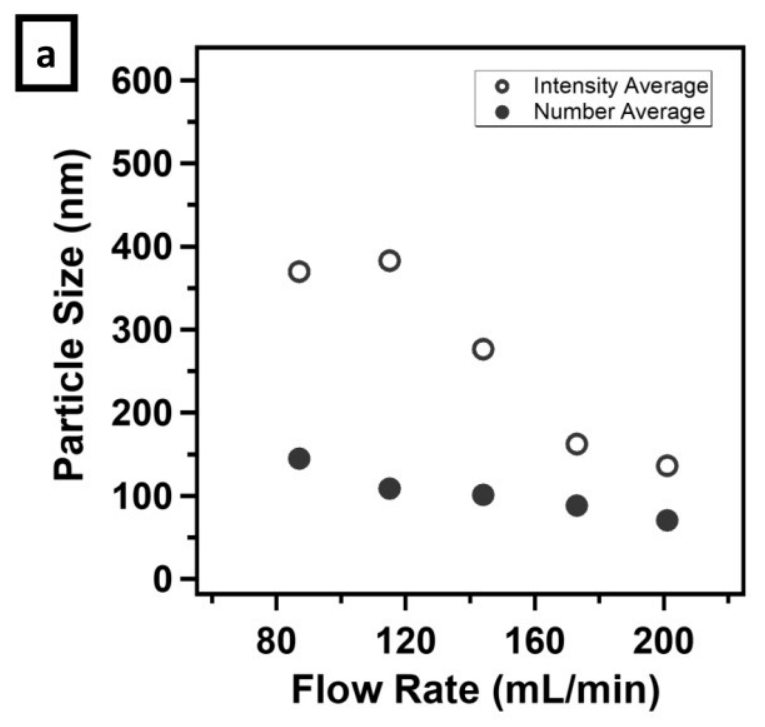

e

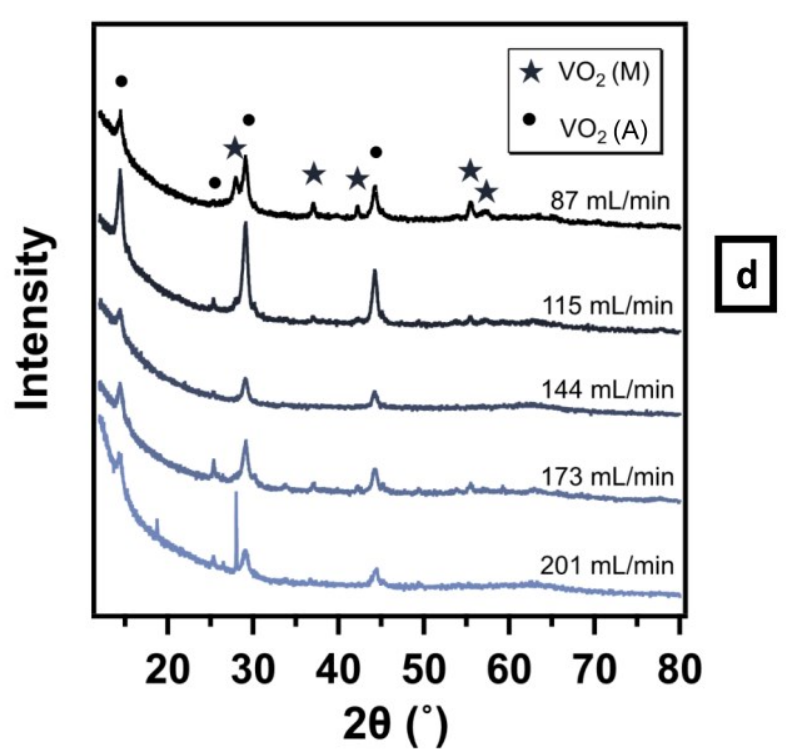

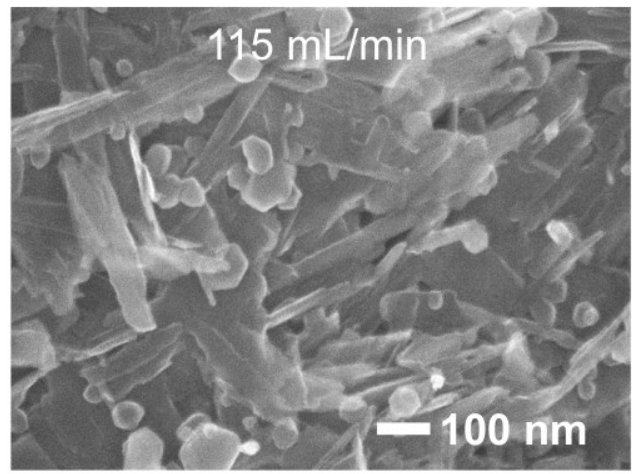
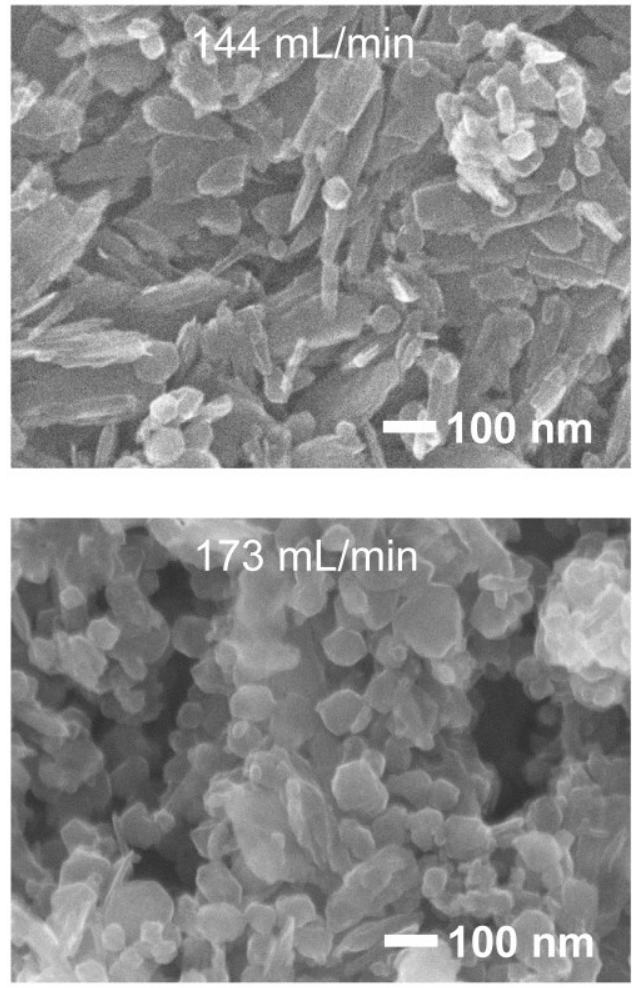

Figure 3. Material characterization results from Study 1, experiment set $\mathrm{A}: \mathrm{scH}_{2} \mathrm{O}$ flow rate effect on $\mathrm{VO}_{2}$ nanoparticle (a) size using DLS, (b-d) morphology using SEM, and (e) crystallinity and phase using XRD.

\section{Effect of Precursor Concentration}

In this parametric study the total system flow rate was kept constant at $173 \mathrm{~mL} \cdot \mathrm{min}^{-1}$ while the vanadium precursor concentration was varied from $0.0356 \mathrm{M}$ (no dilution) to $0.0178 \mathrm{M}$ (2x diluted), 0.01187 M (3x diluted), 0.00712 M (5x diluted), and 0.00356M (10x diluted). Table 3 
presents the key temperatures, residence time, and material characterization results for experiments B1-B5 in this study.

Table 3. Experiments in Study 2: Precursor Concentration Effect on $\mathrm{VO}_{2}$ nanoparticles synthesized in a CFHT reactor - Experimental Parameters, Residence Time, Re, DLS and XRD Material Characterization

\begin{tabular}{|c|c|c|c|c|c|c|c|c|c|c|c|}
\hline \multirow[b]{2}{*}{ Exp. } & \multirow[b]{2}{*}{$\begin{array}{c}{\left[\mathrm{V}^{4+}\right]} \\
(\mathrm{M})\end{array}$} & \multicolumn{2}{|c|}{$\begin{array}{c}\text { Average } \\
\text { Temperature }\left({ }^{\circ} \mathrm{C}\right)\end{array}$} & \multicolumn{3}{|c|}{ Residence Time (s) } & \multirow[b]{2}{*}{$\mathrm{Re}$} & \multicolumn{2}{|c|}{ DLS } & \multirow[b]{2}{*}{$\begin{array}{l}\text { XRD } \\
\text { Phase }\end{array}$} & \multirow[b]{2}{*}{$\mathrm{SEM}^{\dagger}$} \\
\hline & & $\mathrm{T} 4$ & $\mathrm{~T} 5$ & $\begin{array}{l}\text { Mixing } \\
\text { Section }\end{array}$ & $\begin{array}{l}\text { Reactor } \\
\text { Section }\end{array}$ & Total & & $\mathrm{M}_{\mathrm{I}}$ & $\mathrm{M}_{\mathrm{N}}$ & & \\
\hline $\mathrm{B} 1$ & 0.0356 & 388.0 & 381.3 & 0.27 & 1.20 & 1.47 & 13,143 & 162.5 & 88.5 & A & - \\
\hline $\mathrm{B} 2$ & 0.0178 & 387.0 & 381.3 & 0.27 & 1.20 & 1.47 & 13,143 & 132.8 & 42.1 & $\mathrm{~A}$ & FP, $\mathrm{S}$ \\
\hline B3 & 0.01187 & 386.5 & 381.2 & 0.27 & 1.20 & 1.47 & 13,143 & 127.2 & 21.93 & $\mathrm{~A}, \mathrm{M}$ & $\mathrm{S}$ \\
\hline B4 & 0.00712 & 386.2 & 381.4 & 0.27 & 1.20 & 1.47 & 13,143 & 88.6 & 34 & - & $\mathrm{S}$ \\
\hline B5 & 0.00356 & 386.0 & 380.1 & 0.30 & 1.35 & 1.65 & 12,254 & 97.7 & 43.2 & - & S \\
\hline
\end{tabular}

$\uparrow$ Abbreviations used for SEM morphology: FP for Flaky Plates and S for Spheres

Figure 4a shows the DLS particle size where the intensity average particle size decreased from a diameter of $162.5 \mathrm{~nm}$ with no dilution to a diameter of $88.6 \mathrm{~nm}$ with a $5 \mathrm{x}$ dilution factor before increasing in size again at the lowest (10x) dilution. The number average likewise exhibited a general decreasing trend from $88.5 \mathrm{~nm}$ with no dilution down to $21.9 \mathrm{~nm}$ with a $3 \mathrm{x}$ dilution before slightly increasing in size with further dilution (5x and 10x). From the perspective of residence time, the increase in particle size in experiment B5 follows the trend that longer residence time yields larger nanoparticles. Although temperature was typically consistent during all experiments, during experiment $\mathrm{B} 5$, a $1{ }^{\circ} \mathrm{C}$ temperature decrease was exhibited, leading to a $12.4 \%$ increase in the colloidal solution density, and in turn a $12.2 \%$ increase in residence time. The observed increasing number average particle size trend may also be an indication of a plateau, as lower concentrations of nanoparticles tend to hit the limits of the DLS instrumentation and produce noisier data due to the weak signal produced in the sample. While SEM images in Figure $\mathbf{4 b}$ and Figure 4c show the formation of spheres and some flaky plates, the SEM image in Figure 4d corresponding to the $0.0119 \mathrm{M}\left[\mathrm{V}^{4+}\right]$ (3x diluted) sample shows a relatively spherical morphology throughout, indicating that the dilution of the precursor likely aided in reducing the aggregation 
after nanoparticles nucleated, but due to the high solubility and surface energy of the particles at the $\mathrm{scH}_{2} \mathrm{O}$ conditions, smaller particles may be re-dissolving and some degree of Ostwald ripening may still be occurring, therefore contributing to some of the variation in the particle size distribution. ${ }^{33}$ As for the precursor concentration's effect on the $\mathrm{VO}_{2}$, the presence of M-phase (Figure 4e) is the most pronounced at $0.01187 \mathrm{M}\left[\mathrm{V}^{4+}\right]$ as it is evidenced by appearance of peaks corresponding to (011) $\mathrm{VO}_{2} \mathrm{M}$-phase peak. Similar to the case of the higher flow rate sample from Figure 3e, experiment A5, at $201 \mathrm{~mL} \cdot \mathrm{min}^{-1}$, it may be possible that the more diluted precursor samples were able to mix their components more efficiently at high temperature and therefore convert more nanoparticles into $\mathrm{VO}_{2}$ of M-phase. ${ }^{9}$

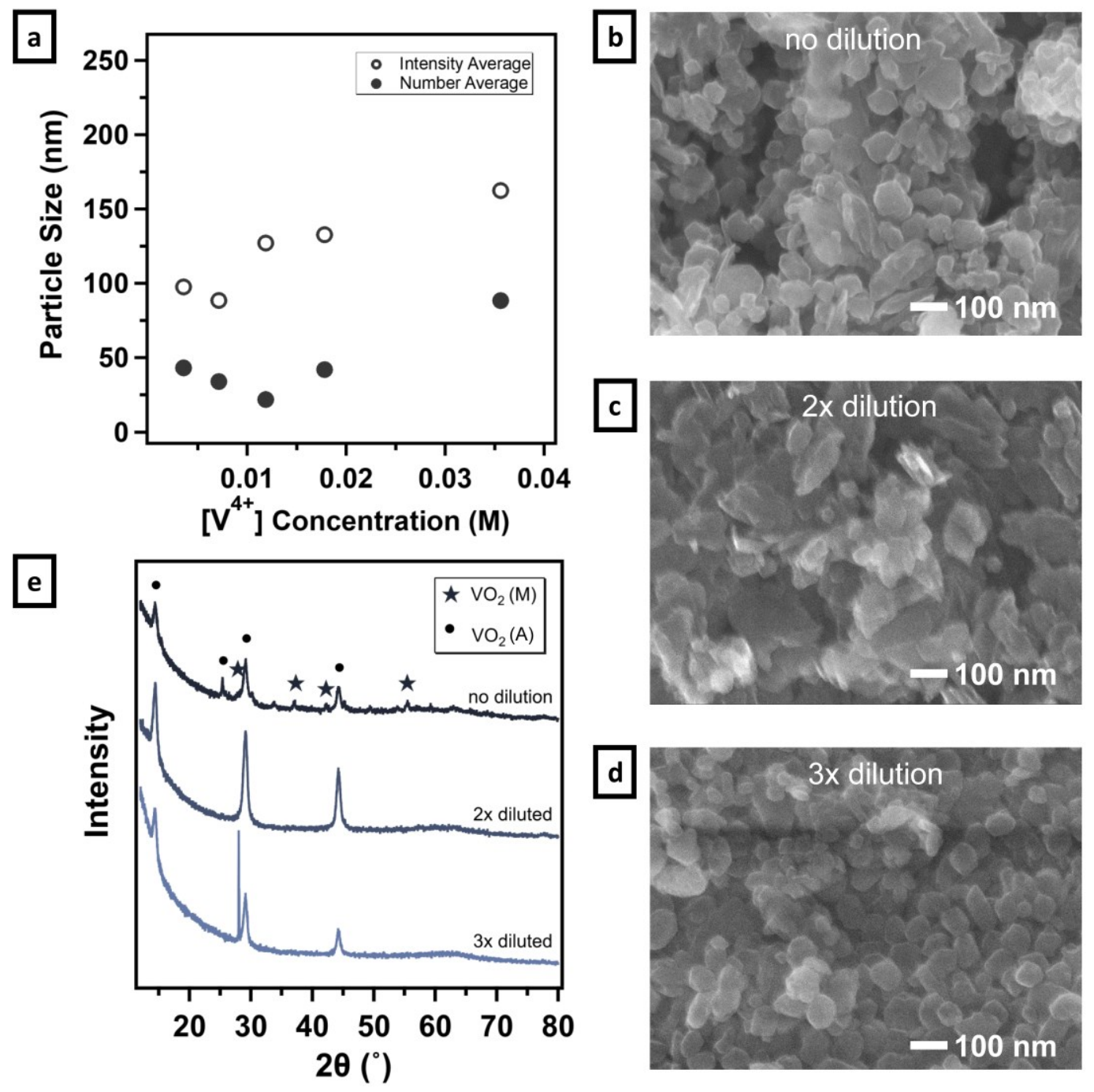


Figure 4. Material characterization results from Study 2, experiment set B: vanadium precursor concentration's effect on $\mathrm{VO}_{2}$ nanoparticle (a) size using DLS, (b-d) morphology using SEM, and (e) crystallinity phase via XRD.

\section{Effect of Supercritical Water Flow Rate at Elevated Temperature}

The third parametric study is focused on the precursor dilution effect. The concentration of the vanadium precursor is selected to maintain the small nanoparticle size, while also keeping the overall nanoparticle yield at a higher end, the latter factor which would be greatly affected by diluting the precursor too much. Thus, for this study the precursor concentration was held constant at $0.01187 \mathrm{M}$ (3x diluted) while varying the system flow rate once again between $87 \mathrm{~mL} \cdot \mathrm{min}^{-1}$ and $201 \mathrm{~mL} \cdot \mathrm{min}^{-1}$. For the first set of experiments, set C, the mixing section's outlet temperature (T5) was similar to previous experiments. In the second set of experiments, set $\mathrm{D}$, the temperature in $\mathrm{T} 5$ is increased by $5.5^{\circ} \mathrm{C}$. Table 4 presents the flow rate, key temperatures, residence times, DLS, XRD, and SEM material characterization results for experiments in this third study.

Table 4. Experiments in Study 3: $\mathrm{scH}_{2} \mathrm{O}$ Flow Rate (Pump 2) and Elevated Temperature Effect on $\mathrm{VO}_{2}$ nanoparticles synthesized in a CFHT reactor - Experimental Parameters, Residence Time, Re, DLS and XRD Material Characterization

\begin{tabular}{|c|c|c|c|c|c|c|c|c|c|c|c|}
\hline \multirow[b]{2}{*}{ Exp. } & \multirow{2}{*}{$\begin{array}{c}\text { Total/ } \\
\text { Pump } 2 \\
\text { Flow Rate } \\
\left(\mathrm{mL} \cdot \mathrm{min}^{-1}\right)\end{array}$} & \multicolumn{2}{|c|}{$\begin{array}{c}\text { Average } \\
\text { Temperature } \\
\left({ }^{\circ} \mathrm{C}\right) \\
\end{array}$} & \multicolumn{3}{|c|}{ Residence Time (s) } & \multirow[b]{2}{*}{$\mathrm{Re}$} & \multicolumn{2}{|c|}{ DLS } & \multirow[b]{2}{*}{$\begin{array}{l}\text { XRD } \\
\text { Phase }\end{array}$} & \multirow[b]{2}{*}{$\mathrm{SEM}^{\dagger}$} \\
\hline & & $\mathrm{T} 4$ & $\mathrm{~T} 5$ & $\begin{array}{l}\text { Mixing } \\
\text { Section }\end{array}$ & $\begin{array}{l}\text { Reactor } \\
\text { Section }\end{array}$ & Total & & $\mathrm{M}_{\mathrm{I}}$ & $\mathrm{M}_{\mathrm{N}}$ & & \\
\hline $\mathrm{C} 1$ & $87 / 58$ & 397.9 & 379.4 & 0.85 & 3.34 & 4.19 & 5,292 & 179.6 & 83.6 & - & FP, S \\
\hline $\mathrm{C} 2$ & $115 / 86$ & 398.7 & 382.0 & 0.40 & 1.67 & 2.07 & 9,078 & 150.6 & 87.7 & - & $\mathrm{FP}, \mathrm{R}, \mathrm{S}$ \\
\hline $\mathrm{C} 3$ & $144 / 115$ & 391.9 & 382.8 & 0.29 & 1.27 & 1.55 & 11,660 & 143.8 & 56.7 & - & FP, S \\
\hline $\mathrm{C} 4$ & $201 / 172$ & 385.1 & 378.6 & 0.37 & 1.67 & 2.04 & 10,934 & 93.1 & 52 & - & $\mathrm{S}$ \\
\hline D1 & $87 / 58$ & 464.6 & 383.6 & 0.51 & 2.01 & 2.51 & 7,177 & 199 & 92.7 & $\mathrm{~A}$ & $\mathrm{FP}, \mathrm{R}, \mathrm{S}$ \\
\hline $\mathrm{D} 2$ & $115 / 86$ & 479.1 & 387.1 & 0.31 & 1.31 & 1.63 & 9,980 & 152.2 & 53.1 & $\mathrm{~A}, \mathrm{M}$ & $\mathrm{FP}, \mathrm{R}, \mathrm{S}$ \\
\hline D3 & $144 / 115$ & 457.2 & 393.1 & 0.21 & 0.93 & 1.14 & 12,870 & 145.4 & 64.3 & - & FP, S \\
\hline D4 & $173 / 144$ & 406.7 & 387.2 & 0.19 & 0.87 & 1.07 & 15,013 & 140.6 & 30.5 & A & $\mathrm{S}$ \\
\hline D5 & $201 / 172$ & 386.1 & 381.3 & 0.23 & 1.03 & 1.26 & 15,271 & 103.7 & 45.8 & A & $\mathrm{S}$ \\
\hline
\end{tabular}

$\uparrow$ Abbreviations used for SEM morphology: FP for Flaky Plates, R for Rods, and S for Spheres

Given the new precursor concentration, the purpose of the first set of experiments in this Study 3, set C, was to confirm previously observed particle morphology characteristics. Similar to 
the previous experiments with increasing system flow rates, a decrease in both intensity average and number average particle size is observed. However unlike in the first parametric study, for this Study 3, the lower concentration precursor seemed to add robustness in the downward trend, even when a temperature decreased in $\mathrm{C} 4$ resulted in an increased residence time closer to that of experiment C2. Through SEM imaging, Figure S8, particle morphology transitioned from a mixture of flaky plates, rods, and spheres to a homogeneous distribution of spherical particles. Unfortunately, predominantly A-phase nanoparticles are observed in the XRD.

Hence, for the second set of experiments within Study 3, set D, the temperature of the colloidal solution exiting the mixing section (T5) was increased to see if the phase composition of the smaller nanoparticles could be fully converted to M-phase. The Phoenix two-stage heater was also adjusted to an upper heater temperature of $450^{\circ} \mathrm{C}$ and a lower heater temperature of $360^{\circ} \mathrm{C}$ to facilitate a higher overall temperature of the mixing section's reactor walls. Figure 5a shows the DLS particle sizes decreased from an intensity average of $199.0 \mathrm{~nm}$ at $87 \mathrm{~mL} \cdot \mathrm{min}^{-1}$ flow rates down to $103.7 \mathrm{~nm}$ at the highest flow rate of $200 \mathrm{~mL} \cdot \mathrm{min}^{-1}$, but no full conversion to M-phase is seen in the XRD. With particular attention to experiment D4, the number average particle size decreased from $92.7 \mathrm{~nm}$ at the lowest flow rate, down to $30.5 \mathrm{~nm}$ a higher flow rate and consequently lowest residence time. D5, while the highest flow rate, exhibited a number average of $45.7 \mathrm{~nm}$ which is thought to increase again in size relative to D3 because of a slightly longer residence time in the reactor. Figure $\mathbf{5 b}$ and Figure $\mathbf{5 c}$ show large flaky plates with a few rods and spheres at these lower flow rates. This mixed morphology indicated some evidence of coalescence and occasional nano-rods that formed, perhaps due to the high surface energy of the particles coupled with an inducing effect from the high pressure and shearing forces. ${ }^{6,34}$ However, for the SEM image corresponding with the sample at $144 \mathrm{~mL} \cdot \mathrm{min}^{-1}$ (Figure 5d), the particles appeared 
to show uniform spheres with sizes appearing to be much smaller than the smallest particles from the earlier parametric studies. However, while the majority of particles were spherical, there was some evidence of coalescence and occasional nano-rods that formed, perhaps due to the high surface energy of the particles coupled with an inducing effect from the high pressure and shearing forces. ${ }^{6,34}$ The slight increase in temperature, as a result of the higher heated $\mathrm{scH}_{2} \mathrm{O}$ and Phoenix heater, did not appear to have a significant effect on the conversion to M-phase of a $0.01187 \mathrm{M}$ (3x diluted) sample. As shown in Figure 5e, the sample at the lowest flow rate tested, $87 \mathrm{~mL} \cdot \mathrm{min}^{-}$ ${ }^{1}$, showed strong A-phase peaks with a slight peak broadening at $2 \theta \cong 29^{\circ}$ which indicated very limited conversion to M-phase. However, the sample at $115 \mathrm{~mL} \cdot \mathrm{min}^{-1}$ had a strong M-phase peak at $2 \theta=28.0^{\circ}$, suggesting that the theory of increased mixing may be the reason for the conversion. When the flow rate was increased to $144 \mathrm{~mL} \cdot \mathrm{min}^{-1}$ there seemed to be a trend back towards $\mathrm{VO}_{2}$ (A) perhaps due to the presence of unreacted reactants; a strong oxalic acid dihydrate peak emerged at $2 \theta=31.7^{\circ}$. 

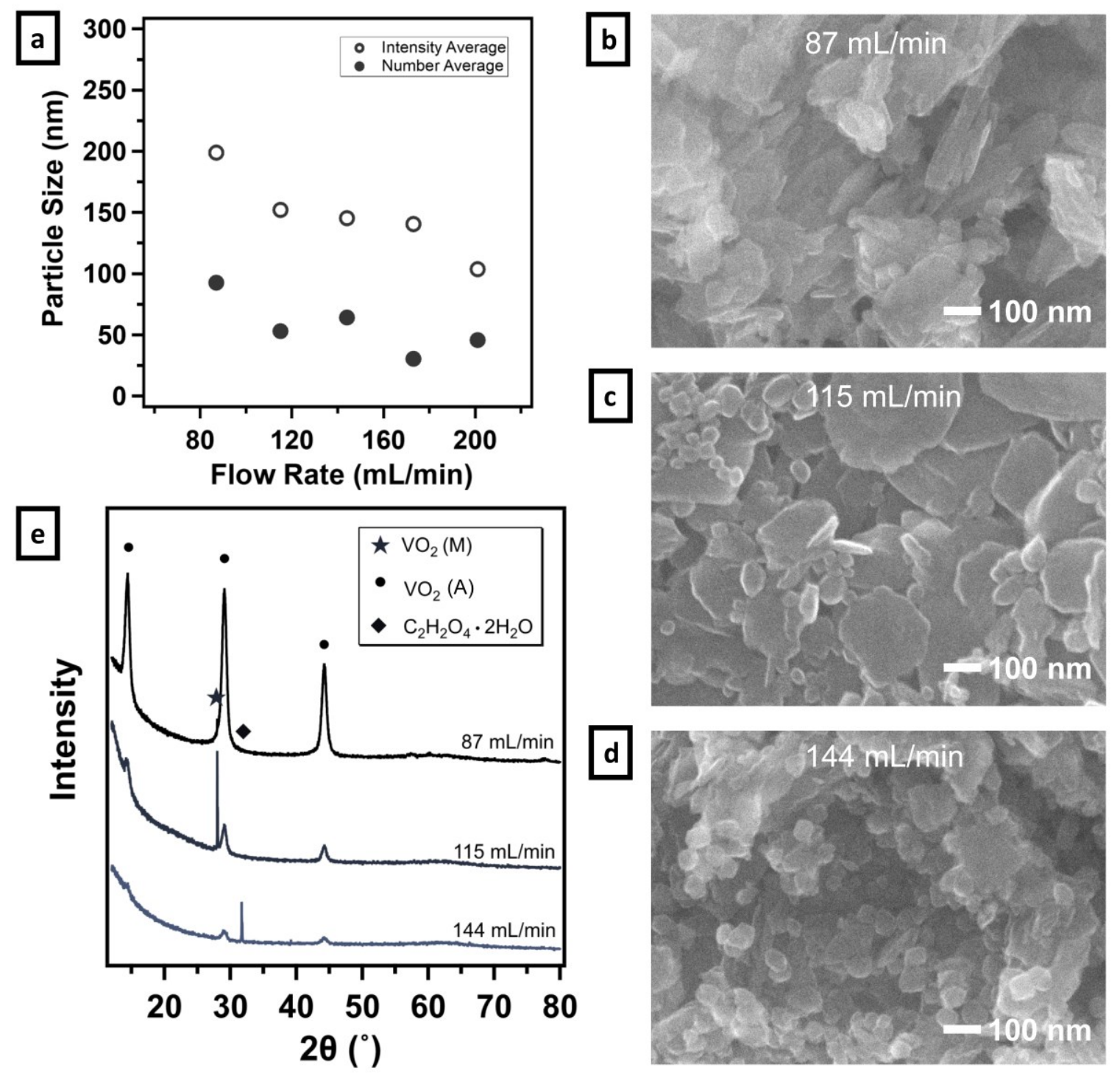

Figure 5. Material characterization results from Study 3, experiment set D: effect of elevated temperature of the supercritical water (Pump 2) and flow rate on $\mathrm{VO}_{2}$ nanoparticle (a) size using DLS, (b-d) morphology using SEM, and (e) crystallinity phase using XRD.

\section{Effect of the Molar Ratio}

Since previous parametric studies allowed us to achieve conditions that lead to the synthesis of $\sim 50 \mathrm{~nm}$ spherical particles, this next fourth study was conducted with the objective to additionally convert these nanoparticles to single, pure $\mathrm{M}$-phase $\mathrm{VO}_{2}$. Combining many of the optimal parameters ascertained from the previous experiments, the study used a $0.01187 \mathrm{M}(3 \mathrm{x}$ diluted) vanadium precursor concentration at 144 and $173 \mathrm{~mL} \cdot \mathrm{min}^{-1}$ system flow rates and elevated 
temperature. Additionally, the molar ratio of the $\mathrm{V}_{2} \mathrm{O}_{5}$ and $\mathrm{C}_{2} \mathrm{H}_{2} \mathrm{O}_{4} \cdot 2 \mathrm{H}_{2} \mathrm{O}$ precursor was changed from a 1:3 to 1:4 ratio. It was observed that experiments D2-D5 had a yellow supernatant after centrifuging, an indication of $\mathrm{V}^{5+}$ present in the solution, it was thus hypothesized that by using a greater amount of reducing agent, the product yield would increase. ${ }^{18}$

Figure 6a shows the particle size distribution of the two experiments, E1 and E2. The particle size intensity averages were $94.6 \mathrm{~nm}$ and $88.8 \mathrm{~nm}$, with number averages at $57.3 \mathrm{~nm}$ and $51.4 \mathrm{~nm}$, which represent system flow rates of 144 and $173 \mathrm{~mL} \cdot \mathrm{min}^{-1}$ respectively. The corresponding SEM images, Figure $\mathbf{6 b}$ and Figure $\mathbf{6 c}$ confirm the particle sizes were around or below $50 \mathrm{~nm}$ in diameter with uniform, spherical morphology. The addition of extra oxalic acid dihydrate appeared to promote the nucleation and hence higher number of smaller sized of synthesized nanoparticles. ${ }^{9}{ }^{35}$ Figure 6d showed that pure M-phase was achieved at the 173 $\mathrm{mL} / \mathrm{min}^{-1}$ system flow rate, but at $144 \mathrm{~mL} \cdot \mathrm{min}^{-1}$, there remained two $\mathrm{VO}_{2}(\mathrm{~A})$ peaks. The peaks at $2 \theta=28.0^{\circ}, 37.0^{\circ}, 42.4^{\circ}, 55.5^{\circ}$, and $56.4^{\circ}$ which correspond to the (011), (200), (-212), (220), and (022) planes in monoclinic $\mathrm{VO}_{2}$ however suggest that this phase dominates. This study indicated that a higher amount of a reductant agent along with a higher reactor outlet temperature are key parameters toward achieving a higher yield of nanoparticles, a result that is also similar to observations reported by Bruyère et al. ${ }^{18}$ The presence of A-phase is observed to vanish at higher flow rates. This observation could be due to the increased availability of water, but as the $\operatorname{Re}$ decreased from 12,496 to 12,254 for E1 and E2 respectively, it is not evident that turbulence played a role in full conversion of the reaction precursors. Another explanation for the residual oxalic acid dihydrate disappearance could be that for experiment $\mathrm{E} 2,173 \mathrm{~mL} \cdot \mathrm{min}^{-1}$ system flow rate, the colloidal solution had about a $28 \%$ longer residence time which allowed for full synthesis to occur 
while still decreasing the particle size compared to experiment E1 at the lower, $144 \mathrm{~mL} \cdot \mathrm{min}^{-1}$, system flow rate.

a

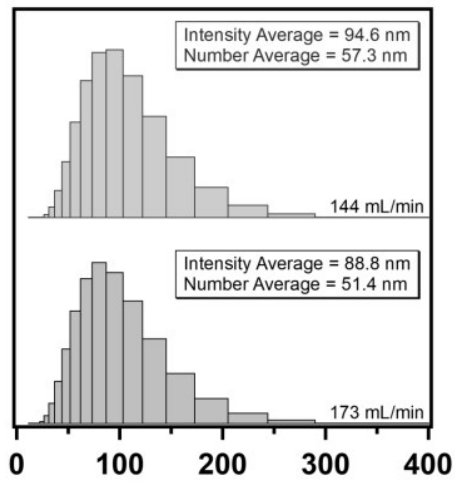

Particle Size Distribution (nm)
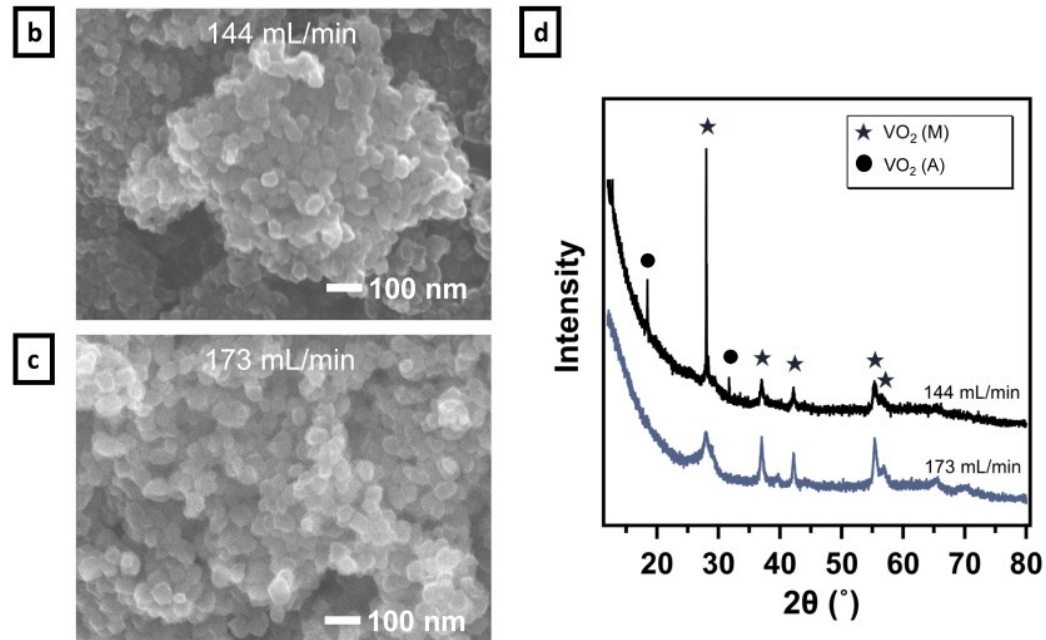

Figure 6. Material characterization results of experiments E1 and E2 in Study 4 that built off of previous experiments, resulting in fully $\mathrm{M}$-phase converted, spherical nanoparticles under $50 \mathrm{~nm}$ in diameter, and where the molar ratio of $\mathrm{V}_{2} \mathrm{O}_{5}$ to $\mathrm{C}_{2} \mathrm{H}_{2} \mathrm{O}_{4} \cdot 2 \mathrm{H}_{2} \mathrm{O}$ was changed from a 1:3 to a 1:4 molar ratio. (a) $\mathrm{VO}_{2}$ nanoparticle size results from DLS, (b-c) nanoparticle morphology results from SEM, and (d) crystallinity phase results from XRD.

\section{Effect of Reactor Section Flow Rate}

The fifth parametric study was completed to confirm results and repeatability of the reactor settings identified in the fourth parametric study as well as test to see the effect that the reactor section flow rate, given from Pump 4, had on the $\mathrm{VO}_{2}$ nanoparticles size and phase. The effect of increasing the flow rate of the colloidal solution at the beginning of the reactor section was studied computationally, showing non-existent effects of Pump 4 at flow rate of $9 \mathrm{~mL} \cdot \mathrm{min}^{-1}$, and experiments were desired to confirm this calculation. ${ }^{36}$ In turn, experiments were carried out over the course of four days with experiment F1 replicating the settings of experiment E2, and experiments F2-F4, eliminating the flow rate from Pump 4; this is achieved by turning the pump off and placing a cap over the inlet location to prevent any backflow. The precursor concentration was held constant at $0.01187 \mathrm{M}$ using a 1:4 molar ratio, and Pump 1, 2, and 3 flow rates were kept 
constant at 10,115 , and $10 \mathrm{~mL} \cdot \mathrm{min}^{-1}$ respectively. Building from the third parametric study and following experiment E2 from the fourth parametric study, higher colloidal solution temperatures, around $387 \pm 2{ }^{\circ} \mathrm{C}$, were observed for this study. Achieving this precision across experiment days shows the stability of the reactor to reach and maintain desired operating conditions near the critical point. Results from experiments are outlined in Table 5.

Table 5. Experiments in Study 5: Reactor Section (Pump 4) Flow Rate Effect on $\mathrm{VO}_{2}$ nanoparticles synthesized in a CFHT reactor - Experimental Parameters, Residence Time, Re, DLS and XRD Material Characterization

\begin{tabular}{|c|c|c|c|c|c|c|c|c|c|c|}
\hline \multirow[b]{2}{*}{ Exp. } & \multirow{2}{*}{$\begin{array}{c}\text { Total/ } \\
\text { Pump 4 } \\
\text { Flow Rate } \\
\left(\mathrm{mL} \cdot \mathrm{min}^{-1}\right)\end{array}$} & \multicolumn{2}{|c|}{$\begin{array}{c}\text { Average } \\
\text { Temperature }\left({ }^{\circ} \mathrm{C}\right)\end{array}$} & \multicolumn{3}{|c|}{ Residence Time (s) } & \multirow[b]{2}{*}{$\mathrm{Re}$} & \multicolumn{2}{|c|}{ DLS } & \multirow[b]{2}{*}{$\begin{array}{l}\text { XRD } \\
\text { Phase }\end{array}$} \\
\hline & & T4 & T5 & $\begin{array}{l}\text { Mixing } \\
\text { Section }\end{array}$ & $\begin{array}{l}\text { Reactor } \\
\text { Section }\end{array}$ & Total & & $\mathrm{M}_{\mathrm{I}}$ & $\mathrm{M}_{\mathrm{N}}$ & \\
\hline F1 & $144 / 9$ & 438.2 & 387.7 & 0.24 & 1.05 & 1.29 & 12,496 & 94.6 & $\begin{array}{l}57.3 \\
\end{array}$ & $M$ \\
\hline F2 & $135 / 0$ & 427.1 & 387.5 & 0.24 & 1.12 & 1.36 & 11,715 & 94.4 & 44.5 & M \\
\hline F3 & $135 / 0$ & 427.5 & 386.9 & 0.24 & 1.15 & 1.39 & 11,635 & 94.6 & 57.9 & M \\
\hline $\mathrm{F} 4$ & $135 / 0$ & 422.1 & 385.3 & 0.26 & 1.21 & 1.47 & 11,431 & 90.0 & 41.6 & M \\
\hline
\end{tabular}

Regarding the residence time across this study, all experiments had about $0.24 \mathrm{~s}$ in the mixing section, with F4 having a longer time in the mixing section because the temperature of the $\mathrm{scH}_{2} \mathrm{O}$ was about $5^{\circ} \mathrm{C}$ lower than for other experiments, leading to a lower temperature of the colloidal solution exiting the mixing section (T5). The residence time for the colloidal solution in the reactor section was the lowest at $1.05 \mathrm{~s}$ for experiment F1; this was due to the use of Pump 4 leading to a higher velocity of the solution. Experiment F1 also had the highest Re of 12,496. For experiments F2-F4 the total residence time was within $11 \mathrm{~ms}$ and the resulting Re was smaller than F1, but still within the turbulence zone: $11,573 \pm 142, \pm 2 \%$ between experiments. Experiment F1 produced nearly identical DLS results to E2, with an intensity average particle size of $94 \mathrm{~nm}$ and a number average particle size of $57 \mathrm{~nm}$, thereby concluding the repeatability of the experimental results and the reliability of the system parameters. The DLS results showed intensity average particle sizes between $90.0-94.6 \mathrm{~nm}$, which was equal to or smaller than the $94.6 \mathrm{~nm}$ that was 
found when there was additional flow rate provided by Pump 4 in experiment F1. Similarly, the number average particle size range of 41.6-57.9 $\mathrm{nm}$ for experiments without the use of Pump 4 shows smaller sizes than when Pump 4 is used. Accordingly, the experimental results are repeatable and the flow rate induced by Pump 4 has a limited effect on the particle properties in the test range. Interestingly, it was seen that at the lower flow rates, and in turn lower Reynolds number the particle size slightly decreased. As all experiments, F1-F4, had about equal residence time in the mixing section, this observation could be due to Pump 4 actually acting to add turbulence and mixing in the reactor section led to particles to experience increased aggregation or growth Ostwald ripening that did not occur in more laminar conditions. For all experiments in this study the $\mathrm{XRD}$ analysis confirmed $\mathrm{VO}_{2}$ products were of a single M-phase, and no residual precursors were observed, see Supporting Information Figure S9.

\section{Effect of Precursor Flow Rate}

The sixth parametric study was conducted over two days to investigate if the amount of precursor introduced into the CFHT reactor system would have a noticeable effect on $\mathrm{VO}_{2}$ nanoparticles. Experiments were conducted, varying the flow rate of Pump 1 to 5, 10, 15 and 19 $\mathrm{mL} \cdot \mathrm{min}^{-1}$. Pump 4 was not used in any of the experiments in this study as the fifth parametric study showed that the $9 \mathrm{~mL} \cdot \mathrm{min}^{-1}$ flow rate added by Pump 4 to the reactor section did not have a noticeable effect on the final $\mathrm{VO}_{2}$ nanoparticle size, and no effect on the phase. Not employing Pump 4 can be advantageous as the amount of water in the colloidal solution was decreased, easing the post processing steps of filtering out the nanoparticles and decreasing waste. The precursor concentration was held constant at $0.01187 \mathrm{M}$ using a 1:4 molar ratio, and the flow rate of Pump 2, and 3 was kept constant at 115 , and $10 \mathrm{~mL} \cdot \mathrm{min}^{-1}$ respectively. Results from experiments are outlined in Table 6. 
Table 6. Experiments in Study 6: Precursor Flow Rate (Pump 1) Effect on $\mathrm{VO}_{2}$ nanoparticles synthesized in a CFHT reactor - Experimental Parameters, Residence Time, Re, DLS and XRD Material Characterization

\begin{tabular}{|c|c|c|c|c|c|c|c|c|c|c|}
\hline \multirow[b]{2}{*}{ Exp. } & \multirow{2}{*}{$\begin{array}{c}\text { Total/ } \\
\text { Pump } 1 \\
\text { Flow Rate } \\
\left(\mathrm{mL} \cdot \mathrm{min}^{-1}\right)\end{array}$} & \multicolumn{2}{|c|}{$\begin{array}{c}\text { Average } \\
\text { Temperature }\left({ }^{\circ} \mathrm{C}\right)\end{array}$} & \multicolumn{3}{|c|}{ Residence Time (s) } & \multirow[b]{2}{*}{$\operatorname{Re}$} & \multicolumn{2}{|c|}{ DLS } & \multirow[b]{2}{*}{$\begin{array}{l}\text { XRD } \\
\text { Phase }\end{array}$} \\
\hline & & T4 & T5 & $\begin{array}{l}\text { Mixing } \\
\text { Section }\end{array}$ & $\begin{array}{l}\text { Reactor } \\
\text { Section }\end{array}$ & Total & & $\mathrm{M}_{\mathrm{I}}$ & $\mathrm{M}_{\mathrm{N}}$ & \\
\hline G1 & $130 / 5$ & 432.6 & 393.7 & 0.22 & 1.02 & 1.23 & 11,648 & 116.2 & 58.6 & $\mathrm{M}$ \\
\hline G2 & $130 / 5$ & 427.7 & 390.7 & 0.23 & 1.08 & 1.31 & 11,508 & 114 & 62.3 & M \\
\hline G3 & $135 / 10$ & 427.5 & 386.9 & 0.24 & 1.15 & 1.39 & 11,635 & 94.6 & 57.9 & M \\
\hline G4 & $140 / 15$ & 401.1 & 383.3 & 0.27 & 1.25 & 1.51 & 11,549 & 95.4 & 45.8 & M \\
\hline
\end{tabular}

For the first two experiments, G1 and G2, the precursor flow rate was decreased from the standard $10 \mathrm{~mL} \cdot \mathrm{min}^{-1}$ to $5 \mathrm{~mL} \cdot \mathrm{min}^{-1}$. DLS results for experiment $\mathrm{G} 1$ was about the same as to experiment G2 for intensity average at $114.0 \mathrm{~nm}$ and $116.2 \mathrm{~nm}$ respectively, but G1 had a larger number average particle size then G2 at $62.3 \mathrm{~nm}$ and $58.6 \mathrm{~nm}$. The smaller particle sizes observed in experiment G1 is thought to be due to the higher temperature of the $\mathrm{scH}_{2} \mathrm{O}$ (T4) and in turn of the colloidal solution exiting the mixing section (T5) being higher than for experiment G2. The higher temperatures resulted in experiment G1 having a lower total residence time of $1.23 \mathrm{~s}$ versus 1.31s for G2. Experiment G1 also had a higher Reynolds number, Re, at 11,648 compared to experiment G2 at 11,508 which highlights that although in general a system with a higher Re yields smaller particles, it is not a perfect predictor, and further studies relating this metric to particle growth would be beneficial. Experiment G3 was conducted at identical conditions as experiment F3 in the fifth parametric study with the precursor flow rate at the standard $10 \mathrm{~mL} \cdot \mathrm{min}^{-1}$, and the DLS and XRD results agreed with the $\mathrm{VO}_{2}$ characteristics in F3. Although the temperature of the $\mathrm{scH}_{2} \mathrm{O}$ (T4) between $\mathrm{G} 2$ and $\mathrm{G} 3$ were nearly identical, the resulting colloidal solution temperature (T5) was about $4{ }^{\circ} \mathrm{C}$ lower for G3. This suggests that it was the increased amount of precursors converting to products in an endothermic reaction that led to the observed decrease in colloidal solution temperature. From the lower temperature in G3, the total residence time was longer at 
$1.39 \mathrm{~s}$, but this did not seem to affect the particle size in the experimental conditions as the intensity average was determined to be $94.6 \mathrm{~nm}$, while the number average was $57.9 \mathrm{~nm}$, smaller and about equal to that of G2, respectively. For experiment G4, the DLS number average reported smaller particles at $45.8 \mathrm{~nm}$ compared to G3. For G4 the total residence time was the longest in the study due to the lower temperature in the mixing and reactor section which also decreased the Re. Overall, it was observed that the increase of precursor flow rate leads to the smaller $\mathrm{VO}_{2}$ nanoparticles. The crystalline phase of the $\mathrm{VO}_{2}$ nanoparticles for all four experiments, G1-G4, was confirmed as pure M-phase. This study successfully showed that under the $\mathrm{scH}_{2} \mathrm{O}$ and the top of mixing section, Pump 2 and 3, and the precursor flow rate (Pump 1) could be increased to produce M-phase $\mathrm{VO}_{2}$ particles sized around $50 \mathrm{~nm} \pm 10 \mathrm{~nm}$ as long as the heat transfer and flow characteristics were scaled appropriately.

\section{Effect of Mixing Section Flow Rate}

For the seventh, and final, parametric study the effect that additional ambient temperature water to the top, or exit, of the mixing section had on $\mathrm{VO}_{2}$ particles was studied by varying the flow rate of Pump 3. The precursor concentration was held constant at $0.01187 \mathrm{M}$ using a 1:4 molar ratio, and the flow rate of Pump 1 and 2 was kept constant at 10 and $115 \mathrm{~mL} \cdot \mathrm{min}^{-1}$, respectively. For the first experiment, H1, both Pump 3 and Pump 4 were set to 10 and $9 \mathrm{~mL} \cdot \mathrm{min}^{-}$ 1, to repeat experiment F1 which itself was a repeat of the optimum conditions defined in experiment E1. For the second experiment, H2, Pump 4 was not used, so as to repeat experiment F3. Then, for the third and fourth experiments, Pump 3 was not used to see if there was a noticeable difference in $\mathrm{VO}_{2}$ properties. The results from experiments are shown in Table 7.

Table 7. Experiments in Study 7: Mixing Section Flow Rate (Pump 3) Effect on $\mathrm{VO}_{2}$ nanoparticles synthesized in a CFHT reactor - Experimental Parameters, Residence Time, Re, DLS and XRD Material Characterization 


\begin{tabular}{|c|c|c|c|c|c|c|c|c|c|c|}
\hline \multirow[b]{2}{*}{ Exp. } & \multirow{2}{*}{$\begin{array}{c}\text { Total/ } \\
\text { Pump 3/ } \\
\text { Pump } 4 \\
\text { Flow Rate } \\
\left(\mathrm{mL} \cdot \mathrm{min}^{-1}\right)\end{array}$} & \multicolumn{2}{|c|}{$\begin{array}{c}\text { Average } \\
\text { Temperature } \\
\left({ }^{\circ} \mathrm{C}\right)\end{array}$} & \multicolumn{3}{|c|}{ Residence Time (s) } & \multirow[b]{2}{*}{$\mathrm{Re}$} & \multicolumn{2}{|c|}{ DLS } & \multirow[b]{2}{*}{$\begin{array}{l}\text { XRD } \\
\text { Phase }\end{array}$} \\
\hline & & $\mathrm{T} 4$ & T5 & $\begin{array}{l}\text { Mixing } \\
\text { Section }\end{array}$ & $\begin{array}{l}\text { Reactor } \\
\text { Section }\end{array}$ & Total & & MI & $\mathrm{MN}$ & \\
\hline $\mathrm{H} 1$ & $144 / 10 / 9$ & 438.2 & 387.6 & 0.24 & 1.05 & 1.29 & 12,496 & 78.9 & 44.5 & - \\
\hline $\mathrm{H} 2$ & $135 / 10 / 0$ & 427.5 & 386.9 & 0.24 & 1.15 & 1.39 & 11,635 & 94.2 & 57.8 & M \\
\hline $\mathrm{H} 3$ & $125 / 0 / 0$ & 435.1 & 390.0 & 0.23 & 1.14 & 1.37 & 11,020 & 96.8 & 55.6 & M \\
\hline $\mathrm{H} 4$ & $125 / 0 / 0$ & 439.3 & 394.9 & 0.21 & 1.04 & 1.25 & 11,225 & 80.1 & 56.2 & - \\
\hline
\end{tabular}

From this experiment set, $\mathrm{H} 1$ confirmed for the second time the repeatability of the optimum set of conditions defined in the fourth study, E1. Experiment $\mathrm{H} 2$ confirmed the repeatability of nanoparticle size results and crystallinity via XRD confirming M-phase. The residence time between $\mathrm{H} 2$ and $\mathrm{H} 3$ is also about the same at $1.37 \mathrm{~s}$, due to the temperature of the $\mathrm{scH}_{2} \mathrm{O}$ being increased, to $435.1^{\circ} \mathrm{C}$. This resulted in lower density of the colloidal solution and faster velocity. This third experiment (H3), where Pump 3 was turned off so that only Pump 1 and Pump 2 are contributing to the total system flow rate, produced nanoparticles with similar intensity average particle sizes as in the $\mathrm{H} 1$ but with an increased number average size of $55.6 \mathrm{~nm}$; more than $10 \mathrm{~nm}$ larger than when Pump 3 is turned on. This suggests that the additional flow rate (and consequently higher Re) does in fact have an effect on the nanoparticle size, acting to decrease the number average. The residence time between $\mathrm{H} 2$ and $\mathrm{H} 3$ was also about the same at $1.37 \mathrm{~s}$, due to the temperature of the $\mathrm{scH}_{2} \mathrm{O}$ being increased, to $435.1^{\circ} \mathrm{C}$, resulting in lower density of the colloidal solution and faster velocity. The increase of temperature for $\mathrm{H} 3$ decreased the Re to 11,020 , showing again that there exists a balance of the flow characteristics in the reactor which yields a given synthesized result. For the fourth and final experiment (H4), all parameters of $\mathrm{H} 3$ are used, with the exception to the temperature of the $\mathrm{scH}_{2} \mathrm{O}$, which is further increased to $439.3^{\circ} \mathrm{C}$ to observe any additional temperature effects on the $\mathrm{VO}_{2}$ particles. As a result, $\mathrm{H} 4$ presented a slightly lower DLS intensity average particle size of $80.1 \mathrm{~nm}$, but the number average particle size remained virtually unchanged at $56.2 \mathrm{~nm}$. From these four experiments, it could be concluded that, 
although not enough sample from $\mathrm{H} 1$ is recovered to measure the phase composition, Pump 3 is an important factor to increase overall system flow rate and Re which in turn help to reach the goal of $\mathrm{VO}_{2}$ nanoparticles less than $50 \mathrm{~nm}$ in diameter. It is thought however, that since $\mathrm{H} 2$ obtained pure M-phase at T4 and T5 temperatures below that of H1, that M-phase would likely be attainable in $\mathrm{H} 1$ as well. There may also be other uses for employing Pump 3 including adding a capping agent to make the nanoparticles, but such study is beyond the scope of this paper.

\section{CONCLUSION}

This work revealed that the single-step, continuous flow hydrothermal reactor approach has the ability to adjust multiple parameters instantaneously, giving them unique advantages over the conventional multi-step batch-methods typically used for many nanoparticle syntheses. Seven parametric studies focusing on understanding the roles of flow rates, temperature, precursor concentration, and composition helped determine the optimal conditions to synthesize $\mathrm{VO}_{2}$ nanoparticles ranging in size from 45-350 $\mathrm{nm}$ and in either the M- or A-phase. For the specific goal of ultrasmall nanoparticles suitable for applications like smart window films, the CFHT reactor system manufactured $\mathrm{VO}_{2} \mathrm{M}$-phase nanoparticles with average number sizes below $50 \mathrm{~nm}$ with precise control. At elevated colloidal solution reaction temperatures between $390-395^{\circ} \mathrm{C}$, full conversion of the $50 \mathrm{~nm} \mathrm{VO}_{2}$ nanoparticles from A- to M-phase is achieved when a 1:4 vanadium pentoxide to oxalic acid dihydrate molar ratio for precursor concentration of $0.01187 \mathrm{M}\left[\mathrm{V}^{4+}\right]$ and a total system flow rate between $125-135 \mathrm{~mL} \cdot \mathrm{min}^{-1}$ for a total residence time between $1.23-1.50 \mathrm{~s}$ and Re between $11,000-12,500$ is used. We found that continuous flow hydrothermal systems demonstrate a promising potential to manufacture nanoparticles, like $\mathrm{VO}_{2}$, with good control of the size, shape, and crystallinity. In the light of high scalability of this approach, the expedited, large-scale synthesis of materials relevant for industrial applications is feasible. While future work 
will focus on exploring the optical properties of the synthesized $\mathrm{VO}_{2}$ (M-phase) nanoparticles, this synthesis process can open new avenues for a multitude of industrial applications for which the world can benefit.

\section{ASSOCIATED CONTENT}

\section{Supporting Information}

The following files are available free of charge.

Details on the experimental setup, details on mixing section geometry, calculations for flow characteristics, detailed experimental thermocouple results, SEM images, XRD patterns.

SupportingInformation.PDF

\section{Author Information}

\section{Corresponding Author}

Jie Li - Applied Materials Division, Argonne National Laboratory; 9700 S. Cass Ave, Lemont, IL 60439, United States; E-mail: jieli@anl.gov

\section{Author Contributions}

$\dagger$ These authors contributed equally.

\section{Funding Sources}

This work was supported by the U.S. Department of Energy Building Technologies Office (BTO) Buildings Energy Efficiency Frontiers \& Innovation Technologies (BENEFIT). Use of the XRD at the Materials Engineering Research Facility at Argonne National Laboratory is supported by the U.S. Department of Energy Office of Energy Efficiency and Renewable Energy. Use of the SEM and centrifuge at the Center for Nanoscale Materials at Argonne National Laboratory is supported 
by the U.S. DOE, Office of Science, Office of Basic Energy Sciences, under contract no. DEAC0206CH-11357.

\section{Notes}

The authors declare no competing financial interest.

\section{Acknowledgement}

The authors thank Janaki Thangaraj for assistance with early replications of the nanoparticle synthesis reactions, as well as creation of the LabView program which monitored the reactor temperature during experiments. M.K. Tran like to thank her PhD advisor, Prof. P.M. Ajayan for his support in new research ventures. E.G. Rasmussen would like to thank her PhD advisors, Prof. John Kramlich and Prof. Igor Novosselov for their support in new research ventures.

\section{Abbreviations}

CFHT, continuous flow hydrothermal; DLS, dynamic light scattering; M-phase, nm, nanometer;

Re, Reynolds number; $\mathrm{scH}_{2} \mathrm{O}$, supercritical phase water; SEM, scanning electron microscopy; XRD, X-ray diffraction 


\section{REFERENCES}

1. Malarde, D.; Johnson, I. D.; Godfrey, I. J.; Powell, M. J.; Cibin, G.; Quesada-Cabrera, R.; Darr, J. A.; Carmalt, C. J.; Sankar, G.; Parkin, I. P., Direct and continuous hydrothermal flow synthesis of thermochromic phase pure monoclinic VO 2 nanoparticles. Journal of Materials Chemistry C 2018, 6 (43), 11731-11739.

2. Li, S.-Y.; Niklasson, G. A.; Granqvist, C.-G., Thermochromic fenestration with VO2based materials: Three challenges and how they can be met. TSF 2012, 520 (10), 3823-3828. 3. Chain, E. E., Optical properties of vanadium dioxide and vanadium pentoxide thin films. ApOpt 1991, 30 (19), 2782-2787.

4. Manning, T. D.; Parkin, I. P.; Clark, R. J.; Sheel, D.; Pemble, M. E.; Vernadou, D., Intelligent window coatings: atmospheric pressure chemical vapour deposition of vanadium oxides. JMCh 2002, 12 (10), 2936-2939.

5. Li, M.; Magdassi, S.; Gao, Y.; Long, Y., Hydrothermal synthesis of VO2 polymorphs: advantages, challenges and prospects for the application of energy efficient smart windows. Small 2017, 13 (36), 1701147.

6. $\quad \mathrm{Yu}, \mathrm{W} . ; \mathrm{Li}, \mathrm{S}$;; Huang, C., Phase evolution and crystal growth of VO 2 nanostructures under hydrothermal reactions. RSC advances 2016, 6 (9), 7113-7120.

7. Leroux, C.; Nihoul, G.; Van Tendeloo, G., From VO 2 (B) to VO 2 (R): Theoretical structures of VO 2 polymorphs and in situ electron microscopy. $P h R v B$ 1998, 57 (9), 5111.

8. Paik, T.; Hong, S.-H.; Gaulding, E. A.; Caglayan, H.; Gordon, T. R.; Engheta, N.; Kagan, C. R.; Murray, C. B., Solution-processed phase-change VO2 metamaterials from colloidal vanadium oxide (VO x) nanocrystals. ACS nano 2014, 8 (1), 797-806.

9. Zhang, H.; Li, Q.; Cheng, B.; Xu, K.; Lan, L.; Zhao, S.; Li, Y.; Cui, T.; Liu, B., A Facile Method to Control the Diameter of Monoclinic Vanadium Dioxide Rods. Journal of nanoscience and nanotechnology 2017, 17 (4), 2791-2795.

10. Calabrese, G. S.; Pissavini, S., From batch to continuous flow processing in chemicals manufacturing. AIChE journal 2011, 57 (4), 828-834.

11. Darr, J. A.; Zhang, J.; Makwana, N. M.; Weng, X., Continuous hydrothermal synthesis of inorganic nanoparticles: applications and future directions. Chem. Rev. 2017, 117 (17), 1112511238.

12. Dunne, P. W.; Munn, A. S.; Starkey, C. L.; Huddle, T. A.; Lester, E. H., Continuousflow hydrothermal synthesis for the production of inorganic nanomaterials. Philosophical Transactions of the Royal Society A: Mathematical, Physical and Engineering Sciences 2015, 373 (2057), 20150015.

13. Murphy, C. J., Sustainability as an emerging design criterion in nanoparticle synthesis and applications. JMCh 2008, 18 (19), 2173-2176.

14. Wu, C.; Zeng, T., Size-tunable synthesis of metallic nanoparticles in a continuous and steady-flow reactor. Chem. Mater. 2007, 19 (2), 123-125.

15. Beyer, J.; Mamakhel, A.; Søndergaard-Pedersen, F.; Yu, J.; Iversen, B. B., Continuous flow hydrothermal synthesis of phase pure rutile TiO 2 nanoparticles with a rod-like morphology. Nanoscale 2020, 12 (4), 2695-2702.

16. Sifner, O., Recommended values of critical parameters of ordinary and heavy-water. Chem. Listy 1985, 79 (2), 199-200. 
17. Sato, H.; Watanabe, K.; Levelt Sengers, J.; Gallagher, J. S.; Hill, P. G.; Straub, J.; Wagner, W., Sixteen thousand evaluated experimental thermodynamic property data for water and steam. J. Phys. Chem. Ref. Data 1991, 20 (5), 1023-1044.

18. Clercq, S. b.; Mouahid, A.; Pèpe, G.; Badens, E., Prediction of Crystal-Solvent Interactions in a Supercritical Medium: A Possible Way to Control Crystal Habit at High Supersaturations with Molecular Modeling. Crystal Growth \& Design 2020, 20 (10), 6863-6876. 19. Adschiri, T.; Kanazawa, K.; Arai, K., Rapid and continuous hydrothermal crystallization of metal oxide particles in supercritical water. J. Am. Ceram. Soc. 1992, 75 (4), 1019-1022.

20. Pioro, I.; Mokry, S., Thermophysical properties at critical and supercritical conditions. Heat transfer: theoretical analysis, experimental investigations and industrial systems 2011, 573-592.

21. Chen, M.; Ma, C. Y.; Mahmud, T.; Darr, J. A.; Wang, X. Z., Modelling and simulation of continuous hydrothermal flow synthesis process for nano-materials manufacture. The Journal of Supercritical Fluids 2011, 59, 131-139.

22. Laaksonen, K.; Li, S.-Y.; Puisto, S.; Rostedt, N.; Ala-Nissila, T.; Granqvist, C.-G.; Nieminen, R.; Niklasson, G. A., Nanoparticles of TiO2 and VO2 in dielectric media: Conditions for low optical scattering, and comparison between effective medium and four-flux theories. Sol. Energy Mater. Sol. Cells 2014, 130, 132-137.

23. Ji, S.; Zhao, Y.; Zhang, F.; Jin, P., Direct formation of single crystal VO2 (R) nanorods by one-step hydrothermal treatment. J. Cryst. Growth 2010, 312 (2), 282-286.

24. Bernstein, M. D.; Friend, R. G., ASME code safety valve rules - a review and discussion. 1995.

25. Kim, H.-A.; Lee, B.-T.; Na, S.-Y.; Kim, K.-W.; Ranville, J. F.; Kim, S.-O.; Jo, E.; Eom, I.-C., Characterization of silver nanoparticle aggregates using single particle-inductively coupled plasma-mass spectrometry (spICP-MS). Chemosphere 2017, 171, 468-475.

26. Reynolds, O., XXIX. An experimental investigation of the circumstances which determine whether the motion of water shall be direct or sinuous, and of the law of resistance in parallel channels. Philos. Trans. R. Soc. London 1997, 174 (174), 935-982.

27. Lemmon, E. W.; Huber, M. L.; McLinden, M. O., NIST reference fluid thermodynamic and transport properties-REFPROP. Version: 2002.

28. Bruce, R. M.; Donald, F. Y.; Theodore, H. O.; Wade, W. H., Fundamentals of Fluid Mechanics. 7 ed.; Wiley: 2012.

29. Rasmussen, E. G.; Kramlich, J.; Novosselov, I. V., Scalable Continuous Flow MetalOrganic Framework (MOF) Synthesis Using Supercritical CO2. ACS Sustain. Chem. Eng. 2020, $8(26), 9680-9689$.

30. Martin, M. J.; Rasmussen, E. G.; Yellapantula, S., Nonlinear Heat Transfer From Particles in Supercritical Carbon Dioxide Near the Critical Point. J Therm Sci Eng Appl 2020, 12 (3), 1-5.

31. Li, X.; Zhang, S.; Yang, L.; Li, X.; Chen, J.; Huang, C., A convenient way to reduce the hysteresis width of VO 2 (M) nanomaterials. NJCh 2017, 41 (24), 15260-15267.

32. Zhang, Y., VO2 (B) conversion to VO2 (A) and VO2 (M) and their oxidation resistance and optical switching properties. Materials Science-Poland 2016, 34 (1), 169-176.

33. De Yoreo, J. J.; Vekilov, P. G., Principles of crystal nucleation and growth. Reviews in mineralogy and geochemistry 2003, 54 (1), 57-93.

34. Lee, J.; Yang, J.; Kwon, S. G.; Hyeon, T., Nonclassical nucleation and growth of inorganic nanoparticles. Nature Reviews Materials 2016, 1 (8), 1-16. 
35. Bruyère, V. I.; Morando, P. J.; Blesa, M. A., The dissolution of vanadium pentoxide in aqueous solutions of oxalic and mineral acids. JCIS 1999, 209 (1), 207-214.

36. Rasmussen, E.; Spurling, R. J.; Tran, M. K.; Li, J., Supercritical Water Flow Influence on Synthesizing Uniformly Sized Nanoparticles. In 73rd Annual Meeting of the APS Division of Fluid Dynamics, Bulletin of the American Physical Society: Virtual, 2020. 